Mirta Galesic (SFI), Daniel Barkoczi (South Denmark University), Andrew Berdahl (U Washington), Dora Biro (U Oxford, UK), Giuseppe Carbone (Polytechnic U Bari, Italy), Ilaria Giannoccaro (Polytechnic U Bari, Italy), Robert Goldstone (U of Indiana), Cleotilde Gonzalez (CMU), Anne Kandler (Max Planck Institute, Germany), Albert Kao (University of Massachusetts Boston), Rachel Kendal (Durham U, UK), Michelle Kline (Brunel University London, UK), Eun Lee (Pukyong National University), Giovanni Francesco Massari (Polytechnic U Bari, Italy), Alex Mesoudi (U of Exeter, UK), Henrik Olsson (SFI), Niccolo Pescetelli (New Jersey Institute of Technology), Sabina J. Sloman (CMU), Paul E. Smaldino (UC Merced), Daniel L. Stein (NYU)

\title{
Beyond collective intelligence: Collective adaptation
}

\begin{abstract}
We develop a conceptual framework for studying collective adaptation in complex sociocognitive systems, driven by dynamic interactions of social integration strategies, social environments, and problem structures. Going beyond searching for "intelligent" collectives, we integrate research from different disciplines and outline modelling approaches that can be used to begin answering questions such as why collectives sometimes fail to reach seemingly obvious solutions, how they change their strategies and network structures in response to different problems, and how we can anticipate and perhaps change future harmful societal trajectories. We discuss the importance of considering path dependence, lack of optimization, and collective myopia to understand the sometimes counterintuitive outcomes of collective adaptation. We call for a transdisciplinary, quantitative, and societally useful social science that can help us to understand our rapidly changing and ever more complex societies, avoid collective disasters, and reach the full potential of our ability to organize in adaptive collectives.
\end{abstract}


Human life is universally structured by assortment into collectives-groupings of various sizes and permanence, from small groups and teams to large organizations and communities (Tajfel, 1981). Collectives shape and are shaped by individual cognitions, pattern of interactions, and the problem structures they encounter and create (Smaldino, 2014). The rapidly increasing scale and complexity of our collectives potentially magnifies threats to our societies which are difficult to understand and predict (Bak-Coleman et al., 2021), including the spread of conspiracy theories (Douglas et al., 2019), denial of facts (Tranter \& Booth, 2015; Schmelz \& Bowles, 2021), extreme polarization (Brown \& Enos, 2021) and violent extremism (Stephens et al., 2021).

Here we argue that, to understand these phenomena and contribute to their solutions, social scientists must better understand the way we collectively adapt to our changing world. We define this collective adaptation as dynamic interactions of social integration strategies, social environments, and problem structures in complex socio-cognitive systems (Figures 1-2). Collectives navigate the ever-changing adaptive landscapes resulting from these interactions and adjust their strategies and network structures to the current constellation of problems. As new problems emerge and become important, collective adaptation can take very different and sometimes unanticipated trajectories. While collectives can be well adapted to one set of problems, when the landscape changes they can perform less well than if they were not adapted in the first place. For example, collectives adapted to stable environmental conditions often fail after a sudden change (Dietz et al., 2003), and groups that work well in a smallscale, "start-up" setting often struggle when they need to graduate to a large-scale organization (Frey \& Sumner, 2019).

This adaptation approach goes beyond the current focus on evaluating performance of collectives with a particular constellation of social integration strategies and network structures, typically solving one problem at a time in a static payoff landscape. As epitomized, for example, in phrases like 'collective intelligence' and 'wisdom' or 'madness of crowds', the evaluation approach focuses on rating groups using specific strategies or network structures as more or less intelligent, depending on the number of different tasks they can solve or their accuracy on a particular task (Galesic et al., 2018; Woolley et al., 2010). However, in many situations of any real-world complexity, optimal solutions can be difficult or impossible to define (Savage, 1972; Simon, 1956) and there are no fixed attractors to which a collective should converge. Collectives instead often grapple with many problems simultaneously, each requiring a different set of strategies and network structures. Adaptive landscapes and the resulting attractors change over time as new problems emerge endogenously and exogenously. As pointed out by Gupta \& Woolley (2021), more than optimizing performance on any particular task, it is important to understand the processes through which collectives adapt to different tasks and contexts.

Our call echoes, on the collective level, Herbert Simon's earlier individual-level call to go beyond studying outcomes of rational thought in relatively simple, static problem situations (Simon, 1976, 1978). We propose to move towards better understanding of multi-scale, dynamically changing interactions that can drive collective trajectories in sometimes unexpected directions. Our approach builds on the foundation of social and ecological rationality (Todd \& Gigerenzer, 2012; Hertwig \& Hoffrage, 2019) and goes further to study the processes of change and adaptation in complex cognitivesocial systems.

We build a conceptual framework for studying collective adaptation that synthesizes relevant knowledge across many thematically overlapping guises in cognitive science, sociology, evolutionary 
anthropology, biology, economics, organizational science, computer science, and statistical physics (Figure 1, Boxes 1 and 2). The framework helps to understand the emergence of collective adaptation as dynamic interactions of its building blocks (Figure 2) on different time scales (Box 3). We provide a selective review of the findings relevant for the different building blocks and their interactions obtained in different disciplines, and outline several modelling approaches that can be used as starting points for a rigorous, quantitative study of collective adaptation. We discuss implications of the conceptual framework and describe novel research questions of both scientific and societal significance that can be investigated through this lens.

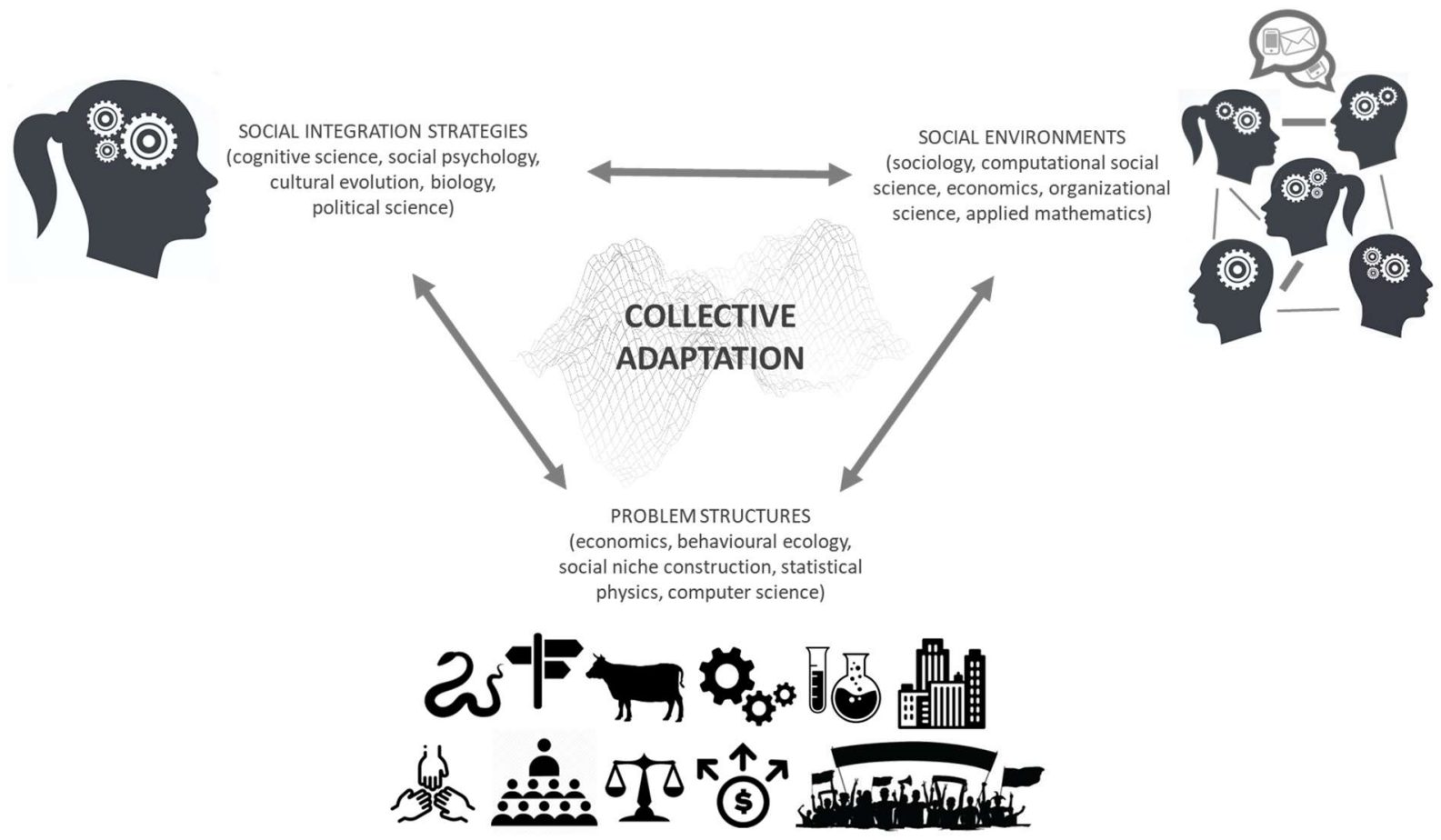

Figure 1. Collective adaptation can be seen as an emergent property of a complex socio-cognitive system driven by dynamic interactions of social integration strategies, social environments, and problem structures collectives face. Collectives take different trajectories when navigating the complex adaptive landscape of these interactions. The system components are wholly entangled, but each has been studied in relatively isolated disciplines, and extant models of collective dynamics rarely include all components. Combining relevant findings and methods in different disciplines (Box 1 ) is critical for understanding collective adaptation, avoiding parallel efforts (Box 2), and building quantitative models that enable answering important outstanding theoretical and practical questions about human sociality.

\section{Building blocks of collective adaptation}

In our framework collectives are represented as complex adaptive socio-cognitive systems (Holland, 1992) that continuously adjust themselves and their environments in response to different problems. Such complex systems cannot be reduced to a set of individual components - they are wholly entangled, exhibiting what Wimsatt (1972) called interactional complexity. However, many aspects of these systems - social integration strategies, social networks, problem structures, and adaptation processes - 
have been studied in separate bodies of literature and developed largely independently in different scientific fields (Figure 1, Boxes 1 and 2). It is therefore useful to first review what is known about each of them in turn, integrating perspectives from different disciplines, before synthesizing them as a sociocognitive system that gives rise to collective adaptation.

\section{Social integration strategies}

Members of collectives often have different beliefs, including different assumptions about states of the world (e.g., whether vaccination is safe), views on moral and political issues (e.g., whether abortion is a matter of personal choice), evaluations of different issues (e.g., whether a particular politician is trustworthy), preferences (e.g., between different ways to tackle climate change), and goals (e.g., increasing their own wealth and prestige). To take stock of their social worlds, understand current social norms, anticipate others' actions, and make decisions, individuals and collectives use different social integration strategies, or cognitive and social algorithms designed to integrate information about beliefs, behaviours, and intentions in social environments (Gigerenzer et al., 2011; Hertwig \& Hoffrage, 2013; Hoppit \& Laland, 2013; Kendal et al., 2018; Steyvers \& Miller, 2015). These strategies form the interface between individual cognition and social networks, providing information needed for the selection and implementation of other social cognitive strategies, from coordination (Grice, 1975; Moussaid et al., 2011), cooperation (Axelrod, 1984; Bowles \& Gintis, 2013), exploration (Hills, et al., 2015; Mehlhorn et al., 2015), to network building and revision (Jackson, 2010). These strategies can be learned individually, influenced genetically, developmentally, and culturally to various degrees, and can be used intentionally or without much conscious thought.

Social integration strategies have been studied in different fields under many different names: social learning strategies (in psychology, cultural evolution, and behavioural ecology), belief updating strategies (in economics, sociology, computational social science, statistical physics), group decisionmaking rules (in psychology and organizational science), voting procedures (in political science and law), and aggregation procedures (in computer science). Despite different names, most of these social integration strategies belong to several basic classes that share common principles, information requirements, and statistical properties. These commonalities have often not been recognized across disciplines, resulting in sometimes inefficient parallel efforts (Box 2). Recognizing these classes is illuminating even though many of these strategies can be modelled as instances of more general processes of Bayesian learning (Krafft et al., 2021; Molleman et al., 2020) or reinforcement learning (Biele et al., 2009; Whalen et al., 2015).

One large class includes frequency-dependent strategies to update beliefs and make decisions based on the number or fraction of others who have a specific belief. Prominent examples are majority, unanimity, and minority strategies. These studies have shown that, depending on the threshold for making a decision, frequency-dependent strategies show different signatures of belief dynamics (Castellano et al., 2009) and cultural diversity (Kandler \& Powell, 2018), and have different consequences for accuracy of individual beliefs and consensus formation (Grofman et al., 1983; Hastie \& Kameda, 2005; Sorkin et al., 1998).

A second class includes averaging strategies, whereby information about other's beliefs and behaviours is averaged, either with or without differential weights for specific individuals (Galton, 1907; DeGroot, 1974; Golub \& Jackson, 2010). Frequently studied strategies for advice taking, including compromising 
between own and others' beliefs, keeping one's own, or adopting another's belief, can be seen as averaging rules with different weights to self and others (Molleman et al., 2020; Yaniv, 2004). Many other rules underlying collective phenomena are essentially also averaging rules in the long run (over time), such as voter rule and Ising models in statistical physics (Castellano et al., 2009), blending inheritance in cultural evolution (Boyd \& Richerson 1985), and contagion rules in epidemiological models of belief dynamics (Newman, 2003).

A third large class of social integration strategies for belief updating includes model-based strategies that use different properties of observed model agents, such as their success in a particular task or overall, their expertise, official rank, prestige, closeness, similarity, or expressed confidence (Kendal et al., 2018). Unlike the strategies in the previous two classes, these strategies give zero weights to most of the available models and focus on a few that seem most appropriate for a given problem. While in principle these models can also be operationalized as averaging strategies where all but one or a few models have zero weights, the cognitive assumptions behind them are different. In averaging strategies everyone in the sample presumably receives at least some attention, but in model-based strategies most others are not even considered. For example, there is robust evidence that people and other animals tend to copy the beliefs and behaviours of those others who have high social status (Henrich \& Gil-White, 2001), are well-liked (Cialdini \& Trost, 1998), and are similar to the observer (Wisdom et al., 2013). Confidence is another important property of models: confident eyewitness testimony is weighted more by members of a jury (Penrod \& Cutler, 1995) and confident people are more influential and trusted (Van Swol \& Sniezek, 2005).

Integration strategies from different classes can be combined, such as when different classes of strategies are used for sampling among social contacts (e.g., by similarity, Almaatouq et al., 2020; Goldstone et al., 2013) and for integrating information from the sample (e.g., by a frequency-based or model-based strategy; Barkoczi et al., 2016). In addition, individuals can use diverse state-based strategies (Kendal et al., 2018), including confidence in own judgments (Pescetelli \& Yeung, 2021) and amount of personal information (Tump et al., 2022) to decide whether to use social information in the first place.

\section{Social environments}

Social environments can be conceptualized as consisting of social networks as well as of various social artefacts that human societies have developed to communicate and cooperate, including a variety of languages and scripts, modes of communication from face to face to social media, oral traditions, physical records of social knowledge from books and videos to monuments and art, and a variety of intangible and tangible institutions that regulate human relationships, from cultural norms to laws (Cialdini \& Trost, 1998; Ostrom, 2010). While the description of all of these artefacts is beyond the scope of this review, they provide important opportunities and constraints for how collectives can communicate and adapt. For example, the overall social context can affect whether others might express their opinions truthfully or with some hidden bias, as is often the case in competitive situations and when it is important to assort with similar individuals in diverse populations (Smaldino et al., 2018).

Different aspects of social environments can affect collective adaptation by influencing which social integration strategies are more successful, supporting or inhibiting the receipt or acceptance of particular information, and supporting or inhibiting the spread of different adaptive responses. In turn, 
social environments continuously change in response to demands of the current problem, past experiences with social contacts, and own social cognitive strategies (Almaatouq, 2020). Collectives can choose to preferentially include or exclude members based on their demographics, expertise, confidence, past cooperative behaviour, perceived membership in an ingroup vs. outgroup, or other factors (Gross \& De Dreu, 2019; Rand et al., 2011).

Here we focus on social networks, conceptualized as the set of other individuals generating social information relevant or at least available for the particular problem. Numerous characteristics of social networks have been studied and excellent reviews exist elsewhere (e.g., Jackson, 2010; Easley \& Kleinberg, 2010). We will mention only four considerations that seem particularly relevant for the process of collective adaptation.

One consideration is the difference between perceived and actual social networks. While parts of social networks can be measured "objectively" by using data on who meets and talks with whom, what eventually matters for explaining how social environments affect beliefs and behaviours is the way these environments are subjectively represented in individual minds (Thomas \& Swaine Thomas, 1928). Social interactions that are actually relevant to a particular collective for a given problem will depend on what people attend to in the moment, their past experiences, and their overall social context (Smith \& Zarate, 1992). Different people can experience the same social network structures differently, depending on how much they like their social contacts (Denrell, 2005), and whether they perceive others as members of their group or as outsiders (Cialdini \& Goldstein, 2004). Similarly, teams with the same objective network structure will have sometimes better and sometimes worse performance when instructed to think of their team as more interdependent (Gonzalez et al., 2015; Martin et al, 2014), and to pay more or less attention to others' solutions (Massari et al., 2019).

Another important consideration is size and connectivity of social networks, because these properties affect the size and composition of social samples people can obtain. While larger groups often support greater innovation and cultural complexity (Henrich 2004; Derex \& Mesoudi 2020), sometimes smaller groups can make better decisions and be more resilient (Kao \& Couzin, 2019; Giannoccaro et al. 2018), and less well-connected networks can promote collective performance on complex problems and truth finding (Derex \& Boyd, 2016; Hahn et al., 2020; Lazer \& Friedman, 2007; Mason et al., 2008). Interdependence of group members in terms of payoffs and shared information further affects collective performance and cooperation (Gonzalez \& Martin, 2011; Gonzalez et al., 2015; Hahn et al., 2019; Martin et al, 2014; Massari et al. 2019). Measures of node centrality such as betweenness predict the spread of information in societies (Banerjee et al., 2013).

A third important consideration is homophily, the phenomenon that people are typically surrounded by similar others (McPherson et al., 2001) because of self-selection, mutual influence, and/or common circumstances (Shalizi \& Thomas, 2011). This affects the samples people receive from their social environments and can produce apparent cognitive biases such as false consensus or false uniqueness (Lee et al, 2019). Because of homophily in their social environments, and especially if they are using frequency-based strategies for integration of social information, people sometimes think of their current status quo as normal and difficult to change (Festinger, 1954), and may try to fit in by adjusting to the perceived norm (Prentice \& Miller, 1993) or be less inclined to support policies that would change the situation (Dawtry et al., 2015). Homophily is also important for emergence of cooperation and collective action (Centola, 2013; Di Stefano et al., 2015). 
A final consideration we highlight is the fact that one's social contacts are, on average, better connected than oneself (so called friendship paradox, Alipourfard et al., 2020; Christakis \& Fowler, 2010; Feld, 1991). Because of this, one's social contacts are more likely to be both observed and copied, spreading their beliefs and behaviours to others, and affected by new contagious trends themselves. This phenomenon both reinforces the value of using one's social contacts as early social signals of what is about to become popular, and triggers a feedback loop whereby copying these valid signals reinforces social contacts' influence on future trends.

Despite the obvious importance of social networks, disciplines differ in the extent to which their models of collective behaviour explicitly include network structure. While the study of social networks has a long and fruitful tradition (Moreno, 1951; Christakis \& Fowler, 2009; Jackson, 2010), in much of psychology and behavioural economics, partially due to the constraints of lab-based experiments, studies have typically focused on small, fully connected groups, or have used descriptions (e.g., vignettes) rather than direct interactions with social environments (Mason et al., 2007). In cultural evolution, networks are often conceptualized as different routes for transmitting information, though they have only recently been included in formal models (Cantor et al. 2021; Derex \& Mesoudi 2020). Instead, researchers more broadly use age as the feature structuring the population and refer to parentto-offspring transmission as "vertical" transmission, peer-to-peer transmission as "horizontal" transmission, and intergenerational transmission that does not involve parents and offspring as "oblique" transmission (Cavalli-Sforza \& Feldman 1981). Who people learn from shifts across their lifespans: children are likely to learn from parents and caretakers, while adolescents and adults are more likely to learn from peers and experts (Deffner \& McElreath, 2022; Kline et al. 2013). These disciplinary differences have been recently blurring with the fast-developing field of computational social science, where interdisciplinary teams study a variety of processes on complex and adapting network structures in web-based studies with human participants and in computational models (Lazer et al., 2020).

\section{Problem structure}

Collectives and the individuals within them face multiple problems at any given time, from avoiding various dangers, developing technological solutions, to organizing and coordinating social relationships. These problems can occur both exogenously from the outside environment, and endogenously from the co-evolution of integration strategies and social environments in response to past problems. For example, modern communication technologies have enabled the development of novel integration strategies (such as various rating systems) and social networks (larger and easier to change) that speed up exchange of useful information. At the same time, these solutions have been a source of many emerging novel problems, such as spread of misinformation and disinformation, development of echo chambers and polarization. Attempts to deal with these problems involve inventing novel strategies and network structures that in turn will likely lead to further problems.

A complete characterization of possible problem structures would require a complete representation of the world around us, which is impossible. However, it is useful to distinguish problem structures that require different social integration strategies and social networks, in particular because many existing papers focus only on a single problem. We provide three examples of such important distinctions that show the importance of comparing several problem types within the same study. One distinction is between problems involving categorical vs continuous judgments. In political science, collective decisions are often studied in tasks that involve a choice between two or more discrete options, such as 
voting for different candidates (Condorcet, 1785). In contrast, much of the 'wisdom of crowds' literature in psychology, economics, and other disciplines typically uses tasks involving continuous judgments, such as guessing the weight of an ox or future inflation rate (Surowiecki, 2005). It is often assumed that the wisdom-of-crowds findings apply also to discrete choices, but while this is true for some of the findings (e.g., that group diversity is typically beneficial for group performance for both kind of tasks, Grofman et al., 1983) it does not hold for others (e.g., that larger groups always outperform smaller groups; Grofman et al., 1984).

Another important distinction is between simple and complex task landscapes. In organizational science and anthropology, and recently in economics and cognitive science, researchers often study problems whose solution space resembles rugged landscapes: local maxima can sway one away from an even better solution elsewhere in the problem space (Kauffman, 1993; Levinthal, 1997). This matters because tasks that involve simple payoff landscapes with one dominant solution benefit from highly interconnected social networks and fast social learning rules. In contrast, tasks that involve rugged landscapes with many local optima can benefit from slower networks and from more individual exploration vs. social learning (Barkoczi \& Galesic, 2016; Barkoczi et al., 2016; Derex \& Boyd, 2016; Goldstone et al., 2013; Lazer \& Friedman, 2007; Carbone \& Giannoccaro, 2015).

A third distinction is between one-shot and repeated problems. In most disciplines, collective performance is studied in one-shot problems. However, most problems unravel over time, with payoffs of different options changing more or less predictably over different time scales. The field of dynamic decision making, a subdiscipline of cognitive science, has focused on these types of tasks, showing for example that individuals and groups with shorter memories and noisier copying strategies can be more successful over time in changing environments (Gonzalez et al., 2015; Lejarraga et al., 2014). Other important distinctions include the way rewards are split among the members of the collective (Ostrom, 2010), distribution of relevant information (Simsek \& Buckmann, 2015), predictability (Olsson, 2021), and speed of environmental change (Aoki \& Feldman, 2014).

Beyond the properties of the specific tasks, problem structures are also defined by more general properties of the global environment that constrains the type and usefulness of possible strategies, networks, and tasks. Economic and political factors, as well as culture and prevailing societal norms are all important sources of these global environmental constraints. For example, some cultures promote the use of frequency-dependent integration strategies such as the majority rule, while others might prefer following a particular individual. In other cultures, social networks cannot exclude certain genders or ethnicities for some problems. And in yet others, problem structures do not include solutions that might be considered elsewhere, such as restricting free speech or the right to bear arms.

\section{Emergence of collective adaptation}

Now we are ready to synthesize social integration strategies, social networks, and problem structures into a complex adaptive system in which these components dynamically interact and adjust to each other. We can visualize this process of collective adaptation in a simplified space of integration strategies, networks, and problems, all evolving together in response to each other over time (Figure 2). 
Time 1

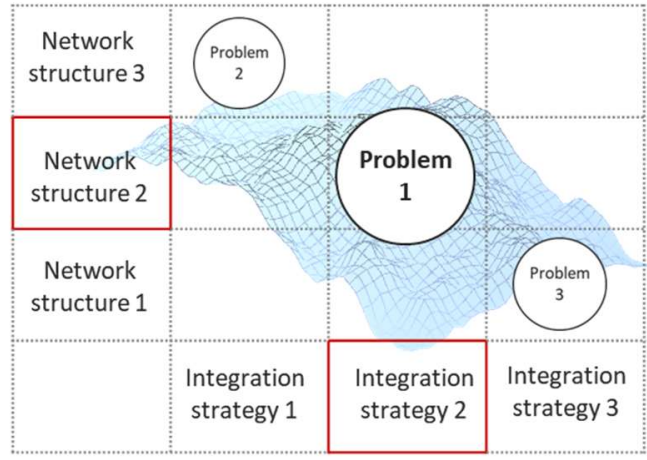

Time 2

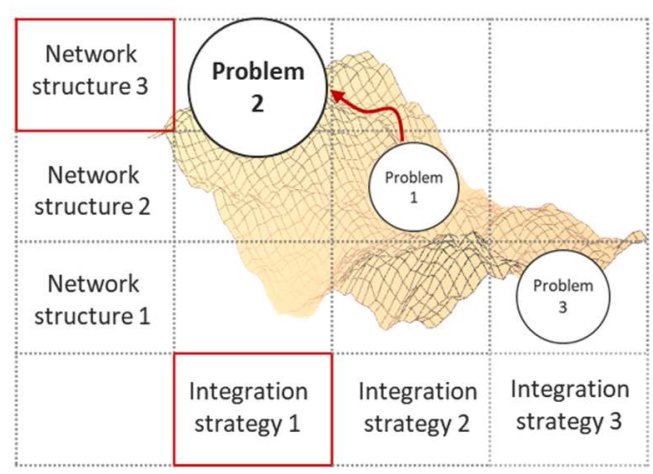

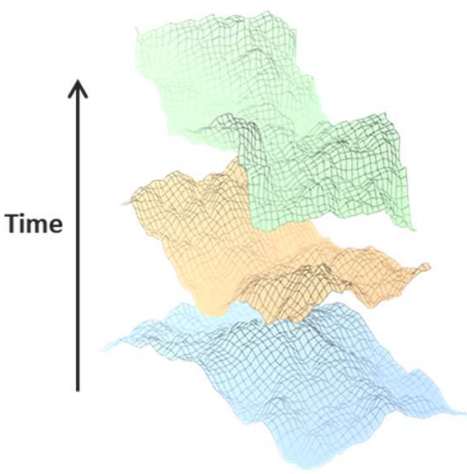

Time 3

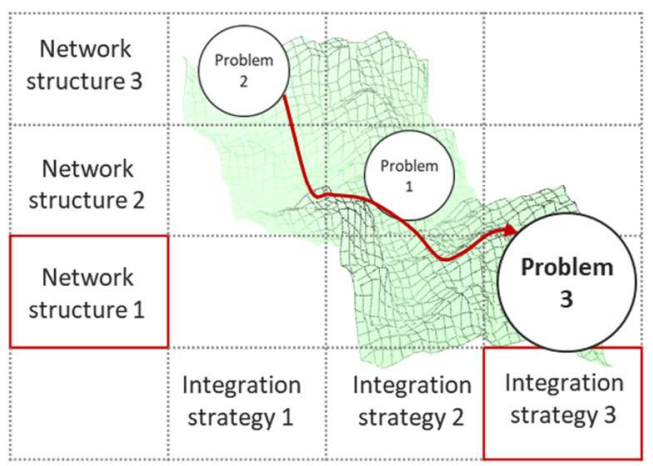

Figure 2. A simplified example of collective adaptation, where a collective 'floats' on the adaptive landscape defined by the possible social integration strategies, social networks, and problem structures. Over time, the landscape changes: different problems emerge and become more or less important to solve. Collectives adapt towards a set of strategies and networks best suited for the problems faced at a given time. The adaptation can take longer when the new landscape requires a very different set of strategies and networks than the collective was adapted to using before.

In this cartoon example, a collective is facing three problems, each best solved by a different combination of integration strategies and network structures (as indicated by the position of problems on the landscape). The underlying payoffs for solving different problems (the adaptive landscape) changes at each time point. At time 1, problem 1 is the most important for most individuals in the collective, and solving it brings the collective to the peak of the adaptive landscape. The collective will therefore tend to adjust their integration strategies and network structures in ways that enable good performance on problem 1, even if this adjustment impairs performance on the other two problems. For example, a collective might be focused on developing complex technologies, and may benefit from relatively loose network structure with occasional exchange of information to find the currently best solution (Lazer \& Friedman, 2007). At time 2, the underlying adaptive landscape has changed either 
because of external environmental changes or endogenous dynamics, and problem 2 now becomes the most important. The collective adapts individual integration strategies and network structures towards those combinations that enhance performance on problem 2. For example, another group might attack the collective, which now has to adapt towards rapid mobilization and unwavering obeyance of a few leaders. This problem usually benefits from a cohesive society with a hierarchical structure that enables rapid transmission of information and commands (Kirke, 2010). At time 3 , the landscape changes again, with problem 3 becoming the most important - for example, adjusting to sudden changes in climate. Now, the collective needs to adapt towards a quite distant set of network structures and integration strategies, enabling both strong local cooperation and global coordination. Over time, the collective 'floats' in this space depending on the current problem structures faced by its members, as well as on their available integration strategies and network structures. Similar scenarios can be imagined for collectives of different sizes and purposes, from families to teams and organizations, to countries, and adaptive changes can occur on different time scales (Box 3).

Of course, in reality this adaptive landscape is high-dimensional and ever-changing. While in the caricature example in Figure 2 we presented integration strategies and network structures as each varying along a single dimension, there are in fact numerous dimensions on which strategies and networks differ. In this high-dimensional space, it might not be necessary to cross 'valleys' of low fitness in order to reach a more adaptive state in the landscape. Rather, collectives could use shortcuts ('fitness ridges') to move from one fitness peak to another (Gavrilets, 2004; Kaplan, 2008). In addition, the adaptive landscapes are constantly changing due to their endogenous dynamics and external factors, and thus are more reminiscent of 'seascapes' (Agarwala \& Fisher, 2019). Nevertheless, the landscape analogy can be a useful starting point for thinking about collective adaptation, provided that one is aware of its limitations (Fragata et al., 2019; Olson et al., 2019). Even if collectives do not need to get stuck in any part of the landscape (or seascape), this analogy makes it clear that knowing the past trajectory of a collective is crucial for understanding its adaptation (or lack of thereof) to new circumstances. It also helps to understand other relevant aspects of collective adaptation, including the impracticality of optimizing for a single problem, collective myopia, and the value of pre-emptive exploration, as we discuss next.

\section{Implications of the collective adaptation perspective}

While vastly simplified, the example in Figure 2 helps to understand five implications of the collective adaptation perspective that distinguish it from more traditional 'collective intelligence' and 'wisdom-ofcrowds' approaches focused on collective performance in specific tasks.

Path dependence. Collectives that currently face the same set of problems can take different trajectories in the space of integration strategies and social environments, depending on the past landscapes they have been adapted to. For example, a country with a strong central government will take a different route toward adapting to a pandemic than a country with weaker and localized governmental structures. In contrast to the more traditional collective intelligence approaches that focus on finding a single point in this space that is best suited for a particular problem, the collective adaptation perspective allows for understanding why some collectives can find it harder to adapt to emerging problems. Their societal structures, belief systems, and problem-solving strategies might have been adapted to very different challenges in the past, and adaptation towards new constellations can be 
difficult because of individual and institutional inertia, lack of relevant knowledge and skills, and high costs of reorganization.

No single "intelligence" dimension. A collective adaptation perspective does not assume a single latent dimension of 'collective intelligence' that would explain a collective's superior performance on many tasks. Rather, it allows for explaining correlations in collective performance as occurring from dynamic interactions of initially unrelated integration strategies and social environments co-occurring over time (akin to explaining correlations in individual performance on intelligence tests by the dynamic interaction of intraindividual processes over time; van der Maas et al., 2006). Consequently, the same measured level of collective intelligence - the general latent factor discovered in correlational analyses of behavioural outcomes (as in e.g., Woolley et al., 2010) - might occur from an interaction of different combinations of underlying cognitive and social processes. The particular combination will depend on the historical trajectory of a particular collective. Because of constant adaptation, it is also possible that a group that was 'intelligent' at one time point later becomes less 'smart' (see section on emerging research questions for examples).

No optimization for a single problem. Current collective behaviour might not be 'optimized' to perform well on any one of the problems it is facing. Instead, collective performance reflects individual and group attempts to perform well enough on at least some of the encountered problems, with different individuals possibly focusing on different problems, and with the repertoire of problems and available strategies and network structures constantly changing. Therefore, collectives can seem 'stuck' in suboptimal behaviours when judged by a single criterion that seems most important to a 'rational' outside observer. For example, collectives can persist with environmentally damaging practices or ethnic discrimination even when these practices seem overall detrimental. In fact, these collectives and individuals within them might be balancing several problems at the same time, such as maintaining system stability and individual security through adhering to existing social norms and hierarchies.

Collective myopia. The constellation of social integration strategies and networks that are best suited for a particular problem might not be immediately obvious or available to the members of a collective used to solving a very different set of problems. For example, even though a particular strategy for integrating social information - for instance a democratic, frequency-based strategy such as following majority - might be best suited for collectively solving today's complex problems, many societies without direct experience in democracy struggle to establish and maintain it. Collectives sometimes need to cross suboptimal stepping stones on the way to discovering better constellations, and can be prone to returning to older, known constellations when this adaptation phase becomes difficult. For example, young democracies with recent experiences in autocratic systems may be prone to returning to those systems (Mechkova et al., 2017).

Benefits of exploring alternative social worlds. It can be beneficial for collectives to explore the space of possible strategies, networks, and problem structures, so that when the environment changes the collective can adapt in the right direction faster. This might be one of the reasons why humans, individually and collectively, often engage in behaviours that appear to not have a particular goal, such as various social games and numerous forms of storytelling (from myths and epics to theatre and cinema) aimed just as much at describing the current world as at exploring hypothetical alternative worlds. Among other benefits, these activities enable exploration of the space of possible solutions and 
rehearsing collective responses to different situations, enabling faster collective adaptation in times of quick, significant changes.

\section{Studying collective adaptation}

\section{Existing findings on interactions of building blocks}

Many interactions between the building blocks of collective adaptation have been documented in different, largely disconnected literatures. To foster transdisciplinary integration of this knowledge in our overall framework, we review findings of their dyadic and triadic interaction patterns. Further studies of collective adaptation can build on these existing findings. Each of the findings in this section can be seen as one point on the complex landscape that collectives must navigate. A main question for further research is to understand and model how collectives traverse between these different points.

Interaction of social integration strategies and problem structures. People can flexibly adapt their integration strategies to the requirements of a particular task (Kendal et al., 2018). Humans and other animals show a continuum of flexibility, from facultative switching in response to developmental cues (e.g. learning socially when pregnant to avoid the risks of asocial learning, or learning from peers rather than parents when early developmental environments contain markers of stress) and social network position (Rawlings et al. 2017), to the individual learning of social learning (e.g. learning via reinforcement that copying others for particular problems is beneficial) and the social learning of social learning (learning from others how to learn from others; Mesoudi et al., 2016) which may lead to cultural variation in the use of social learning strategies (Glowacki \& Molleman 2017; Mesoudi et al. 2015). Reward experiences in a particular task can promote more or less social learning, with individual exploration being more pronounced at early stages of collective problem solving and with declining payoffs whereas exploitation of previous solutions is more likely later on and when payoffs are good (Billinger et al., 2014; Daniels et al., 2017; Giannoccaro et al., 2020; Sloman et al., 2019). In turn, this affects individual and group performance in fast changing environments, where individual exploration is more useful than copying past solutions (Lejarraga et al., 2014). Cognition can also adapt to specific tasks that have been particularly consequential in our evolutionary past, making some concepts easier to learn and transmit in a group (Claidiere \& Sperber, 2007; Cosmides \& Tooby, 1992; Gigerenzer \& Hug, 1992; Henrich \& McElreath 2003). For example, urban legends or gossip that contain survival, social, or emotional information are transmitted better than those that do not (Miton et al., 2015; Stubbersfield et al. 2015).

While social integration strategies can be adapted to the task at hand, the best strategies for a given task may not be available to all collectives or all individuals within a collective because of historical and cultural constraints. For example, organizations and governments might be designed to integrate information in a particular way (e.g., through a set of more or less democratic institutional structures) which can be difficult to change. Such entrenched integration rules can lead to problems of their own making. For example, an organization where decisions are made by a central authority can find it difficult to deal with problems requiring diverse opinions. A society facing a problem that requires collective action but whose decision structures emphasize individual and minority rights may find it difficult to build the consensus needed to solve the problem.

Interaction of social integration strategies and social environments. The interplay of social network structures and different integration strategies can significantly change the dynamics of belief spread and 
collective adaptation (Gross \& Blasius, 2008). For example, the fitness of different cooperative strategies (Boyd \& Lorberbaum, 1987) and social learning strategies (Rendell et al., 2010) is highly dependent on the distribution of competing strategies in the population. Inference strategies that produce high variance in individual solutions perform better when used in groups than when individuals use them alone (Olsson, 2021). Diversity of solutions in general promotes collective performance (Brush et al., 2018; Page, 2008). Integration strategies and social environments interact so that strategies relying on less social learning perform better in more connected networks, and those that rely on more social learning perform better in less connected networks (Goldstone et al., 2013; Barkoczi and Galesic, 2016; Becker et al., 2017).

Even more than social integration strategies, social networks can be difficult to change because of physical infrastructure, cultural and historical reasons, familial and financial connections. Collectives can be stuck with particular network structures that can make solving novel problems difficult. At the same time, collectives might experience exogenous pressures on network structures, from abolishing or establishing segregation laws to the growth of social media technologies. These changes can require novel social integration strategies, such as learning new metacognitive cues for recognizing true and false information coming from novel social environments (Kozyreva et al., 2020), and appropriately judging cues such as confidence (Becker et al., 2017; Pescetelli et al., 2016) or past performance (Molleman et al., 2020) to decide how much to take into account others' opinions (Heyes, 2018).

Interaction of social environments and problem structures. For complex tasks, sparse social networks in which information spreads slowly typically lead to better collective decisions (Derex \& Boyd, 2016; Lazer \& Friedman, 2007), whereas for simpler tasks well-connected networks perform better. Smaller groups can be more accurate than larger groups when making a series of categorical decisions (Galesic et al., 2018; Kao \& Couzin, 2014, 2019), but large groups are typically better than smaller groups when it comes to making accurate continuous judgments (Page, 2008). Interacting groups can achieve better outcomes on tasks that require pooling of unshared knowledge (Stasser \& Titus, 1985). While problems can shape networks, changes in social networks in turn can produce a host of new unanticipated problems (Bak-Coleman et al., 2021), from misinformation and polarization to conflicts and inability to solve collective problems.

Interaction of social integration strategies, social environments, and problem structures. In addition to the dyadic interactions described so far, all three components interact and adjust to each other. For example, in response to problems such as outgroup threat or increased uncertainty, collectives might change integration strategies from democratic to more authoritarian and at the same time tighten up their networks to purge perceived intruders and speed up information flow (Janis, 1973; Jost et al., 2003). In turn, problems that collectives face can emerge and change depending on integration strategies and network structures incentivized in a given society (Yamagishi, T., \& Hashimoto, 2016). For example, increased polarization of opinions can give rise to fragmentation of social networks and reduced social trust, which in turn creates problems related to managing common resources such as climate (Fairbrother et al., 2019) and solving collective problems such as pandemics (Bargain et al., 2020). Social environments and problem structures also interact with and shape the effectiveness of integration strategies (Sloman et al., 2021). To decide which strategy to use in different social and problem contexts, individuals and groups use metacognitive cues about their own and others' past and likely future performance (Hayes, 2016, 2108). One such cue can be the speed of response of different group members: those who have better individual information are likely to react first, allowing the 
others to learn socially from them, which can be particularly advantageous when costs of errors are high or when the group situation is competitive (Tump et al., 2022). Strategy choice can also be affected by cultural norms (e.g., following an authority figure might be more valued in some societies, while in others consensus decisions based on frequency-dependent or averaging strategies may be more valued), network properties (strategies such as majority rule require more interconnected networks than some model-based strategies such as following a leader; Lu et al., 2021), and task characteristics (e.g., whether it is more important to find a quick collectively acceptable solution or find the best possible solution; Barkoczi \& Galesic, 2016).

\section{Promising modelling approaches}

How can we go beyond verbal explanations to model in a rigorous way how collectives navigate the complex adaptive landscapes of integration strategies, social environments, and problem structures? Ideally, models of collective adaptation should be as simple as possible to enable understanding and stimulate further theory development even when they are wrong (as ultimately all models are). For example, the landscape analogy and related models obviously miss some important aspects of collective adaptation, but these errors are easy to grasp and can shed light on aspects that need more theorizing. More opaque and complicated models can be more accurate but less conducive to further insights. There is no one best model or analogy for complex social phenomena such as collective adaptation each analogy will have limits and associated conceptual baggage (Gigerenzer, 1991; Olson, 2019). It is therefore fruitful to explore many different analogies and modelling techniques and compare their predictions of real-world phenomena.

Furthermore, models of collective adaptation should be implemented mathematically or computationally and produce quantitative predictions of future individual and collective trends. Beyond mathematical models, system dynamics models can be used to better understand relationships and feedback loops between different building blocks of collective adaptation (Forrester, 1968; Maani \& Cavana, 2007). Agent-based models allow implementation of diverse integration strategies on the level of individuals embedded in different social environments and problem structures (Acerbi et al., 2021; Bowles \& Gintis, 2013; Epstein, 2016; Macy \& Willer, 2002; Miller \& Page, 2009; Smaldino 2023). Computational models should be inspired and - importantly - constrained by theory and evidence about human cognition and sociality.

Models should ideally be able to describe and predict collective performance across different contexts, by finding dimensions along which different tasks, strategies, and networks structures can be compared (e.g., task complexity, strategy class, network size and interconnectedness). Models can also go beyond mere performance and try to predict collective ability to adapt. In most real-world situations, collectives need to juggle several different tasks simultaneously in continuously changing environments. Adaptation therefore might be better expressed as the ability to anticipate, cope with, and/or reorganize in response to changes in problem structures, strategies, and social environments (Konstantinidis et al., 2020), or more broadly as a version of social resilience (Holling, 1973; Saja et al., 2021).

Finally, as all models will be at least partially wrong, it is imperative to continuously test their assumptions and predictions in real-world situations. One must compare different models that can predict similar trends and explore when and why they make reasonable predictions and when they fail. 
Fortunately, scientists have never had access to so much empirical data about different aspects of human cognition and sociality as today. It is now more convenient than ever to obtain data from group experiments and observational studies (Salganik, 2019), historical and archaeological data, ethnographic data, mobile phone data (Schläpfer et al., 2021) and other sensing methods (Loreto et al., 2016), to longitudinal surveys (Dalege et al., 2016; van der Does et al., 2021), and analyses of large textual corpora and other by-products of human interactions (e.g., Barron et al., 2018; Kozlowski et al., 2019). These sources of data, in particular those which include longitudinal information about problems, strategies, and network structures faced by a particular collective, can all be used to study collective adaptation.

While describing different modelling paradigms is beyond the scope of this paper, here we mention several paradigms that are good candidates for developing models of collective adaptation.

Evolutionary models. The collective adaptation perspective is fundamentally dynamic and evolutionary in nature. This does not mean that it is focused on the genetic or biological roots of collective behaviour, only that it is focused on how collective systems respond to endogenous and exogenous pressures and shocks. Adaptation need not involve biological reproduction and can be based on social transmission occurring on time scales from moments to many generations (Heyes, 2018; Jablonka and Lamb, 2004; Richerson \& Boyd, 2008). Evolution can be used as an analogy to help model how collectives adopt different social integration strategies given their collective history, current cognitive and social capabilities, and momentarily attended problem structures (Boyd \& Richerson 1985; Cavalli-Sforza \& Feldman 1981; Kallens et al., 2018; Laland 2004; Mesoudi, 2016). Evolutionary models can help reveal how natural selection can lead to effective group-level collective responses, while operating on selfish individuals (Torney et al., 2011; Hein et al., 2015). One aspect of collective adaptation that these models typically lack is network structure, in particular complex structures that occur in the real world. Recent modelling efforts have begun to study the co-evolution of network structures and integration strategies (Deffner et al., 2021; Cantor et al., 2021), generalist or specialist problem environments (Smolla \& Akçay, 2019), and cooperation (Akçay, 2018).

Bayesian reasoning. While fully Bayesian models of social cognition are too computationally intensive to be cognitively plausible, this analogy can be useful to understand existing and develop new social integration heuristics that resemble optimal balance between exploration and exploitation (Molleman et al., 2020; Krafft et al., 2021). For example, mathematical models of optimal decision-making using Thompson sampling have been successful in modelling cooperative multi-armed bandit problems with varying communication constraints (Dubey \& Pentland, 2020; Pentland, 2021). To be useful for studying collective adaptation, these models could be extended to more complex and simultaneous conflicting problems, as well as to other network structures.

Statistical physics. One can also model collective adaptation using analogies with systems of particles as studied in statistical physics. Models based on the statistical physics framework typically involve a collection of agents connected in a particular way, who can choose between different states according to specified rules. Statistical physics models can incorporate psychological concepts (Dalege et al., 2018; Galesic et al., 2021; Redner, 2019) such as cognitive dissonance (energy), uncertainty or lack of attention (temperature), subjective representations of networks (linkages), and belief integration strategies (updating rules). Other physics analogies that have been used to study collective adaptation are percolation (Morone \& Makse, 2015), diffusion (Tump et al., 2020), Monte Carlo methods (Perc et al., 2017), and quantum physics (Haven \& Khrenikov, 2013). A related analogy that has been successfully 
used in many models of aspects of collective adaptation, in particular belief dynamics, is epidemiology (Bettencourt et al., 2006; Daley \& Kendall, 1964). To be suitable for studying collective adaptation, these models should involve mechanisms (meta-level strategies) for switching between integration rules and network structures as problem environments change.

New paradigms for modelling collective adaptation. Because collective adaptation involves an interaction of cognition, social environments, and problem structure, modelling it will likely require connecting several frameworks, each useful for a particular component or time scale. One example is Tump et al.'s (2022) combination of drift diffusion cognitive models of individual and social learning with an evolutionary process that selects parameters of drift diffusion models that are best adapted to particular group structures and problems with different costs of errors. Another example is Cooney et al.'s (2022) work on modelling the evolution of sociality that combines epidemiological models, a replicator equation, and adaptive dynamics models to study evolution on three different time scales. We believe that successful modelling frameworks will involve such combinations of models suitable for different aspects of collective adaptation. Computational models can be particularly suitable for such integration.

\section{Research questions emerging from the collective adaptation framework}

The collective adaptation framework enables researchers to begin answering a number of critical questions for social science and our society. These questions are difficult to investigate within the collective intelligence framework where intelligence is seen as a fixed attribute of teams in a static problem environment, and where research is often confined to disciplinary silos. The lens of collective adaptation helps to think about these complex problems in a new systematic way. Each of these questions can be reframed as a problem of finding a new combination of integration strategies and social environments after being adapted to a different problem structure in the past. Researchers can use models and empirical studies to simultaneously explore these building blocks of collective adaptation.

Why is it sometimes hard for collectives to reach seemingly obvious solutions to a particular problem? Researchers and other citizens often wonder why their collectives cannot seem to find solutions to problems such as climate change, mass shootings, racism, or pandemics. To many individuals it seems obvious what needs to be done, but collective trajectories seem difficult to steer in the right direction. The collective adaptation framework offers several insights about possible reasons. One is that collectives try to solve many different problems at the same time, and integration strategies and networks suitable for solving one problem can interfere with solving other problems. For example, collectives might try to maintain stability by preserving existing strategies and network structures, even though those might have been developed for very different problems in the past (e.g., Electoral College in the United States or veto rights in the United Nations). A related reason is that different groups within collectives often have different preferences, and strategies used to integrate these preferences are not adapted to the problem at hand but are chosen because of historical, cultural, or power-related reasons. For example, collective decisions such as those about climate change or abortion are made not by a frequency-based strategy such as majority rule, but rather by following specific influential members, chosen because of financial or historical institutional advantages. Finally, collectives can be stuck in an unfavourable part of the problem landscape, where moving in any direction brings temporarily worse performance before any improvement is achieved. For example, dealing with climate change might 
reduce employment or profits of key members of the collective, making them reluctant to initiate changes that would ultimately lead to better outcomes for all.

\section{Why do some collectives develop successful ways of coping with a specific problem and others seem} to fail? As it became obvious during the COVID-19 pandemic, some countries managed to achieve a high level of vaccination and relatively low rate of deaths, while others did not (BBC News, 2022). Many other problems, from achieving democracy to reducing corruption, can be more or less difficult to solve for different collectives. While the collective adaptation framework does not provide immediate answers, it suggests that a way to understand these problems is by understanding the historical trajectories that the collectives have navigated while solving past problems. In particular, the social integration strategies and network structures that they have developed in the past might be impairing their ability to cope with novel problems. For example, collectives that traditionally engaged in more individual learning and had decentralized networks might be less likely to accept government-enforced vaccination (Schmelz, 2021).

Why do some successful collectives experience reduced performance over time? Sometimes, initially high-performing teams become worse over time. Aside from regression to the mean and related issues such as the noisy relationship between performance and true ability (Denrell, 2005), the collective adaptation framework offers further avenues of inquiry. For example, early success can make a team more tightly interconnected over time (Mullen \& Cooper, 1994) - in turn impairing its performance on further complex tasks where diversity of opinions is needed for success (Lazer \& Friedman, 2007; Massari et al. 2019). And, increased cooperation in social networks can support the formation of more long-range social ties, which can create the conditions for the collapse of cooperation (Akçay, 2018).

How do collectives change their integration strategies and network structures to adapt to different problems? The collective adaptation framework points to the crucial need for studying the meta-level strategies that collectives use for these decisions. While, as described before, there is much research on the social integration strategies and network structures that individuals and collectives use to solve different problems, there is little research on meta-level strategies that collectives use to switch between different strategies and networks depending on problems they face. In individual decision making it has been shown that individuals can adapt their social integration strategies to the task at hand (Payne et al., 1988; Rieskamp \& Otto, 2006; Griffiths et al., 2019), with strategies depending on cognitive abilities (Mata et al., 2007), time pressure (Rieskamp \& Hoffrage, 2008), past performance (Billinger et al., 2014), and knowledge of cues (Binz et all., 2021). In social contexts, meta-level strategies have been studied in advice taking (Soll \& Larrick, 2009; Molleman et al., 2020) and in teamwork (Giannoccaro et al., 2020), but more research is still needed on how collectives decide to use different strategies (Siders \& Pierce, 2021), and in particular how they decide to restructure their networks (but see Akçay 2018; Smolla \& Akçay, 2019; Almaatouq 2020). Answering these questions is further complicated by the presence of social norms and more formal institutions that limit the set of strategies and network structures that collectives can choose from. A promising perspective is the transactive systems framework (Gupta \& Woolley, 2021), which describes how collectives use their memory, attention, and reasoning systems to sense changes in their environment and coordinate actions. Another promising framework is Bayesian collective learning, based on the mathematical theory of optimal decision making, which can be used to anticipate and justify different heuristic strategies for social integration and network updating in circumstances of limited and erroneous knowledge about others' strategies and network connections (Pentland, 2021). Finally, group and collective emotions such 
as perceived threat from an outgroup or group pride can be powerful triggers for quick restructuring of a collective's network structure and the way it integrates social information (Goldenberg et al., 2020; Bacaksizlar Turbic \& Galesic, 2022).

\section{Can we anticipate new problems that might emerge because of the way societies adapted to past} problems? Collective adaptation perspective suggests that one can anticipate problems that collectives could encounter in the future by understanding what problems they had to solve in the past. Adaptation to previous environments will determine their currently used integration strategies and network structures, and affect the ease with which collectives can adapt to new contexts. For example, more tightly knit collectives and those that follow a few dominant members rather than using frequencybased integration strategies might be more likely to encounter difficulties in solving complex problems that require diverse opinions about possible solutions. As another example, groups experiencing threat can adopt a more homogeneous mindset that is prejudiced towards intruders and allows for quick collective action, but that at the same time facilitates the spread of harmful beliefs that can endanger the groups in the long run (Turner \& Horvitz, 2001). Of course, predictions of collective adaptation trajectories can be inherently limited by the complexity of the underlying socio-cognitive systems, but it is useful to explore the extent of gains that can be made by theoretical and methodological development.

\section{How can we reduce less desirable consequences of emerging collective problems? Better} understanding of complex adaptive socio-cognitive systems that give rise to undesirable consequences (e.g., spread of misinformation, hate speech, extremism, and violence) could ultimately allow collectives to adjust their trajectories in order to reduce the likelihood of such consequences. This would be an improvement to the current societal response to these phenomena, which is focused mostly on alleviating the consequences once they occur rather than preventing them. Ideally, the collective adaptation framework could be leveraged for societal impact in areas such as enhancing or developing cultures of sustainability, promoting beneficial health behaviours, and promoting a healthy societal dialogue. At the same time, it might help societies to avoid adversarial attempts to manipulate collective decisions and behaviours.

\section{Outlook}

The collective adaptation perspective goes beyond the traditional idea of collective intelligence, by explicitly acknowledging and modelling several critical aspects of real-world collective behaviour: path dependence, impossibility of optimization, collective myopia, and seemingly aimless exploration of alternative worlds. More generally, the collective adaptation perspective does not search for a generally intelligent collective but asks instead, "What pathways might collectives take in pursuit of their various goals, given the problems they have been adapted to in the past?". Understanding the dynamic interactions of integration strategies, social environments, and problem structures opens a path towards studying important scientific and societal questions such as why collectives fail to reach seemingly obvious solutions, how they adapt their integration strategies and social network structures to novel problems, and how they can avoid less desirable future pathways. We hope this article will inspire researchers to develop and empirically test rigorous models of collective adaptation based on the rich knowledge accumulated across fields, thus contributing to a transdisciplinary, quantitative, and societally useful social science. Only such social science can help people to understand our rapidly 
changing and ever more complex societies, avoid collective disasters, and reach the full potential of our ability to organize in adaptive collectives.

\section{Box 1. Overlapping views of collective adaptation}

Aspects of collective adaptation have been studied in different disciplines under different names:

Collective intelligence. Also occasionally called "swarm intelligence", collective intelligence has a long history (Graves, 1842; Pumroy, 1846) and is extensively studied today. Prominent definitions include "groups of individuals acting collectively in ways that seem intelligent" (Malone \& Bernstein, 2015) and "the general ability of a group to perform a wide variety of tasks" (Woolley et al, 2010). More recently, researchers have identified different collective processes underlying collective intelligence, such as transactive memory, attention, and reasoning systems (Gupta \& Woolley, 2021) and skill congruence (Riedl et al., 2021) which provide groups the capability to better translate individual ability into collective performance (Ostrowski et al., 2022). Collective intelligence has been studied extensively in organizational science (Woolley et al., 2015; Malone et al., 2009; Massari et al., 2019), cognitive science (Galesic et al., 2019; Granovisky et al., 2015; Jayles et al. 2020; Kurvers et al. 2016), business (Bothos et al., 2012; Tauscher, 2017), managing intellectual capital (Secundo et al., 2016), and crisis management (Hernantes et al., 2013; Turoff et al., 2013), among other fields. This approach also underlies efforts in statistics and computer science to use the power of ensembles (Breiman, 1994) and distributed computation (Sole et al., 2019). Emergence of collective intelligence has been modelled using analogies from different fields, from statistical physics (De Vincenzo et al., 2017) to neuroscience (Daniels et al., 2017).

Social learning. Humans and other animals often learn from others (Bandura, 1977; Hoppitt \& Laland, 2013; Kendal et al, 2018). This can be a less costly way than asocial learning to acquire valuable information about good solutions to a variety of tasks, from finding food and mates to solving complex technological and social problems. Many of the strategies described in the social learning literature have also been described in the literatures on collective problem solving and group decision making (Hertwig \& Hoffrage, 2013; Hoppitt \& Laland, 2013; Kendal et al., 2018). A related body of literature is that on advice taking (Bonaccio \& Dalal, 2006; Yaniv, 2004), investigating in which circumstances people choose to follow the advice, follow their own mind, or do something in-between.

Collective problem solving. A large literature in behavioural ecology and evolutionary anthropology investigates how humans and other animals accumulate information that no single individual can acquire on their own. For example, relatively simple movement rules allow group members to reach a consensus about the timing and spatial direction of movement (Conradt \& Roper, 2010); naïve individuals can be successfully led to a new food source or migrate in the correct direction (Couzin et al., 2005); collective movement can average the preferences of the individuals in the group (Berdahl et al. 2018), and allow groups to respond to environmental gradients that group members are not able to sense individually (Berdahl et al. 2013), in both cases improving the quality of the resulting decision; and animals in groups can discover new routes that individuals cannot (Sasaki \& Biro 2017). This collectively generated knowledge, when retained at the individual level, is known in biology as 'collective learning,' and represents an emergent form of social learning (Biro et al. 2016). In cognitive science, collective problem solving has been studied in modelling and experimental studies in the context of decisions from experience (Gonzalez et al., 2015; Lejarraga et al., 2014) and exploration-exploitation tradeoffs (Hills et al., 2015; Mehlhorn et al., 2015).

Group decision making. This broad field at the intersection of psychology, management, and applied mathematics (Kerr \& Tindale, 2004) has contributed a vast array of theories and findings on interacting groups, from research on group decision making algorithms (Caklovic \& Kurdija, 2017; Dalkey, 1969; Hastie \& Kameda, 2005; Saaty, 1989) to 
the value of exchange of information (Stasser \& Titus, 1985). Group decision making has also been extensively studied in biology (Conradt \& List, 2009).

Wisdom of crowds. When and why does the combined judgment of multiple individuals outperform the average and sometimes the best individual in the group? This question is closely related to those asked in collective problem-solving and group decision making literatures. Studies of "wisdom of crowds" phenomena range from early seminal essays of Condorcet (1783) and Galton (1907) to recent studies in judgment and decision making (Davis-Stober et al., 2014), cognitive psychology (Danileiko \& Lee, 2017), political science (List \& Puppe, 2009), forecasting (Mellers et al., 2014), economics (Pivato, 2017), law (Devine et al., 2001), sociology (Shi et al., 2019), and biology (Kao \& Couzin, 2019). Topics of study are the value of experts (Budescu \& Chen, 2015; Mannes et al., 2014; Olsson \& Loveday, 2015), diversity (Davis-Stober et al., 2014; Page, 2008), and adaptive network structures (Almaatouq, 2020).

Game theory. The tools and insights developed within this very broad field are relevant for collective adaptation. In particular, evolutionary game theory is a framework that can be used to model how social integration strategies and networks adapt to task environments over time (Friedman, 1998; Newton, 2018) and how the outcomes of evolutionary games depend on the structure of multilayer networks (Wang et al., 2015). Another game theoretical perspective that provides a good starting point to begin understanding collective adaptation are game theoretical models of social dilemmas and problems of collective action (Heckathorn, 1996; Ostrom, 2010). For example, Gonzalez et al. (2015) used the Prisoner's Dilemma to advance the cognitive theory of decisions from experience from individual to dyads, and Moreira et al. (2013) showed how social networks and collective problems co-evolve.

Group minds. Not only do we process information in groups, but the group itself is a rich information processing system that is often much greater than the sum of its parts (Goldstone \& Theiner, 2017). For example, work on transactive memory looks at how information is stored within and flows between different members of the group, enhancing the amount of information the group can store and leverage in complex problem-solving tasks (Hinsz et al., 1997; Lewis \& Herndon, 2011).

Belief dynamics. Diverse disciplines have been studying beliefs change over time and on social networks, developing a number of analytic and computational models of belief dynamics (Centola \& Macy, 2007; Epstein, 2014; Galesic et al., 2021; Pentland, 2014; Proskurnikov \& Tempo, 2017; Vallacher, Read, \& Nowak, 2017). These models can help understand why in certain societies new beliefs - such as opinions on climate change or vaccines - spread more quickly than in others, sometimes leading to polarization and other times to consensus, and occasionally leading to backlash effects.

Evolutionary anthropology. Several approaches use explicitly evolutionary models to study collective behaviour and changes, typically on a theoretical level and on longer time scales. Researchers have taken a number of different perspectives. For example, cultural evolution uses analogies with Darwinian evolution to study cultural change (Mesoudi, 2016) and how changes in human societies accumulate and build on each other (Mesoudi \& Thornton, 2018). Social learning mechanisms are an essential element of cultural evolution and studying various forms of social learning has been a theoretical and empirical focus for the field (Kandler \& Powell, 2018). Behavioural ecology focuses on the analysis of fitness benefits of different behaviours and cultural practices. By assuming that humans and other animals aim to maximize their fitness, which can be defined in different ways, studies in this field aim to understand how particular socioecological contexts lead to different kinds of behaviours, including different mating and parenting strategies, cooperative and competitive strategies, etc (Ready \& Price, 2019). Cultural niche construction aims to explain how people adjust the composition of their social networks and their institutions to foster beneficial collective behaviours such as cooperation (Ryan et al., 2016; Yamagishi \& Hashimoto, 2016).

Many other literatures are relevant for understanding of collective adaptation, but space constraints prevent us from describing them in any detail here. These include but are not limited to crowd psychology (Le Bon, 1895), 
collective behaviour (Turner \& Killian, 1957), social contagion (Young, 2009), information cascades (Bikhchandani et al., 1992), social diffusion (DeGroot, 1974; Rogers, 1962), herd behaviour (Banerjee et al., 1992), social choice (Arrow, 1950), forecasting (Tetlock \& Gardner, 2016), jury decisions (Hastie et al., 2013), and peer production (Benkler et al., 2015).

\section{Box 2. Parallel efforts}

Because different aspects of collective adaptation have been studied in relatively isolated disciplines, basic concepts and principles are often rediscovered.

Frequency-dependent social integration strategies. Many disciplines have studied frequency-dependent social integration strategies over the last few centuries, from early work in political science (Condorcet 1785; Heinberg, 1932), statistics (Penrose, 1946), psychology (conformism; Asch, 1955), to economics (Plott, 1967), law (Penrod \& Hastie, 1979), organizational science (Nitzan \& Paroush, 1982), cultural evolution (Boyd \& Richerson, 1985), animal learning (Laland, 2004), computer science (Parhami, 1994), statistical physics (Krapivsky \& Redner, 2003), biology (King \& Cowlishaw, 2007), and sociology (Centola \& Macy, 2007). For example, 'complex contagion' models that are rightfully suggested as more appropriate than 'simple contagion' in many situations can be viewed as frequency-dependent rules that have been studied in other disciplines under different names (Guilbeault et al., 2018).

Majority rule. While each discipline has contributed useful insights, some basic statistical regularities have been rediscovered a number of times. One such regularity has been described already by Condorcet in 1785: Groups using a majority rule can outperform any individual member in finding the correct option, with group accuracy increasing with group size. This can be represented as a cumulative probabilistic process, as described by Poisson (1837) and Laplace (1886; see Gelfand and Solomon, 1973). However, this work was largely forgotten in social sciences until the second half of the $20^{\text {th }}$ century (Grofman et al., 1984), when the same relationship between group size and accuracy was rediscovered in cultural evolution (Boyd \& Richerson 1985), psychology (Hastie \& Kameda, 2005), sociology (Centola \& Macy, 2007), biology (King et al., 2007), and statistical physics of belief dynamics (Krapivsky \& Redner, 2003). Further, more counter-intuitive findings such as that smaller groups can in some circumstances perform better than large groups on tasks with discrete options have also been obtained independently in political science (Grofman et al., 1984), biology (Kao \& Couzin, 2014), and cognitive science (Galesic et al., 2018).

Belief dynamics. Similarly, studies of belief formation, change, and spread are conducted largely independently in disciplines ranging from social and cognitive psychology, evolutionary anthropology, political science, sociology and computational social science, economics, philosophy, and logic, to statistical physics and computer science (e.g., Axelrod, 1997; van Benthem, 2011; Castellano et al., 2009; Centola, 2018; Friedkin et al., 2016; Golub \& Jackson, 2010; Vallacher et al., 2017; Watts \& Dodds, 2007). Some of these disciplines focus more on social learning processes underlying belief dynamics, others on the structure of social networks on which the dynamics occur; some disciplines study models that are more qualitative and others more quantitative; some employ empirical research while others focus on theory. The same outcomes such as consensus, polarization, fragmentation, and zealotry have been studied from different perspectives, with none of the disciplines alone understanding the full picture of the underlying complex socio-cognitive system that gives rise to belief dynamics.

Network effects. Parallel efforts in different disciplines can also contribute innovative new insights. For example, social network structures and their implications for individual and collective outcomes have been studied in sociology and social psychology for a long time. With the increased ease of measuring and modelling various phenomena on social networks, researchers from other disciplines such as statistical physics and computer science made a number of additional contributions, revisiting biases due to homophily such as false consensus (Ross et al., 
1977; Lerman et al., 2016), describing novel implications of the friendship paradox (Feld, 1991, Cantwell at al., 2021), and extending work on small worlds and degrees of separation (Milgram, 1967; Watts and Strogatz, 1998).

\section{Box 3. Time scales of collective adaptation}

Collective adaptation can emerge at evolutionary, historical, and contemporary time scales. In evolutionary time, collectives of humans and other animals have evolved adaptations that enable quick reactions to life-threatening situations. For example, many animal collectives can detect and react to predators through relatively simple rules of alignment which might have evolved partially as a response to predation threat (Couzin \& Krause, 2003). Human collectives too exhibit fairly common changes in cognitive processing and network structure when faced with a real or perceived group threat, including rapid collective coordination of beliefs and behaviours, increased altruistic tendencies towards in-group members, and an increased tendency to follow a group leader rather than explore possible solutions on one's own (Bonanno \& Jost, 2010; Fisher, 2006), which might have been adaptive in situations of real outgroup threats that posed a strong selective pressure in our evolutionary past (Bowles, 2009).

In historical time, human collectives have been adapting to perpetuating social problems through informal and formal institutions, social norms, and cultural artefacts, which provide a default for social integration strategies, network structures, and problem representations appropriate in different situations and domains of life (Yamagishi \& Hashimoto, 2016). Many societies have developed institutions and organizations dedicated to managing common goods, resolving conflicts and curbing violence, regulating mate choice, electing leaders, and regulating private property (Ostrom, 1990). Cultural and organizational norms impose further constraints on how individual members can communicate and make decisions. For example, some societies are more likely to follow an established leader's opinion, while others are more prone to establishing consensus (Henrich et al., 2015). Some collectives maintain open lines of communication between all members of the society while others prohibit communication between certain parts of society (different castes or genders). Voting systems from direct democracy to electoral college to authoritarianism constrain how much individuals can participate in collective decisions. And, societal artefacts from vocabulary and number systems to stories and monuments can strongly influence whether a society finds something problematic and how it represents possible solutions.

Finally, collectives explore possible pathways contemporaneously, often starting from evolutionary and historical defaults, but also by reasoning, learning, and innovation throughout individual and collective lifespans to make sense of current circumstances and possible opportunities for solutions. Much of the current research in collective adaptation, from organizational science and wisdom of crowds to collective intelligence and animal learning, studies how groups explore task landscapes and decide on best ways to move forward. The contemporaneous time scale is the focus of this review.

\section{Author Contributions}

All authors contributed to conceptualization and writing of the manuscript.

\section{Acknowledgments}

This research was partially supported by grants NSF BCS 1745154, NSF DRMS 1757211, and NSF SocPsych 1918490 . The funders had no role in any part of the preparation of the manuscript. Any opinions, findings and conclusions or recommendations expressed in this material are those of the authors and do not necessarily reflect the views of the funding agencies. 


\section{References}

Acemoglu, D., Ozdaglar, A. \& ParandehGheibi, A. (2010). Spread of (mis)information in social networks. Games and Economic Behavior, 70, 194-227.

Acerbi, A., Mesoudi, A. \& Smolla, M. (2021). Individual-based models of cultural evolution. A step-by-step guide using R. Taylor \& Francis.

Agarwala, A., \& Fisher, D. S. (2019). Adaptive walks on high-dimensional fitness landscapes and seascapes with distance-dependent statistics. Theoretical population biology, 130, 13-49.

Akçay, E. (2018). Collapse and rescue of cooperation in evolving dynamic networks. Nature Communications, 9(1), 1-9.

Alipourfard, N., Nettasinghe, B., Abeliuk, A., Krishnamurthy, V. \& Lerman, K. (2020). Friendship paradox biases perceptions in directed networks. Nature Communications, 11, 707.

Almaatouq, A., Noriega-Campero, A., Alotaibi, A., Krafft, P. M., Moussaid, M., \& Pentland, A. (2020). Adaptive social networks promote the wisdom of crowds. Proceedings of the National Academy of Sciences, 117(21), 11379-11386.

Aoki, K., \& Feldman, M. W. (2014). Evolution of learning strategies in temporally and spatially variable environments: a review of theory. Theoretical Population Biology, 91, 3-19.

Arkes, H. R., Gigerenzer, G., \& Hertwig, R. (2016). How bad is incoherence? Decision, 3, 20-39.

Arrow, K. J. (1950). A difficulty in the concept of social welfare. Journal of Political Economy, 58(4), 328-346.

Asch, S. E. (1955). Opinions and social pressure. Scientific American, 193(5), 31-35.

Axelrod, R. (1997). The dissemination of culture: A model with local convergence and global polarization. Journal of Conflict Resolution, 41(2), 203-226.

Axelrod, Robert (1984), The Evolution of Cooperation, Basic Books.

Bacaksizlar Turbic, G. \& Galesic, M. Group threat, political extremity, and collective dynamics in online discussions. doi: 10.48550/arXiv.2206.04987.

Bak-Coleman, J.B., Alfano, M., Barfuss, W., Bergstom, C.T., Centeno, M.A., Couzin, I.D., ... Weber, E.U. (2021). Stewardship of global collective behaviour. Proceedings of the National Academy of Sciences.

Bandura, A., \& McClelland, D. C. (1977). Social learning theory (Vol. 1). Prentice Hall: Englewood cliffs.

Banerjee, A. V. A simple model of herd behaviour (1992). The Quarterly Journal of Economics, 107, $797-817$.

Banerjee, A., Chandrasekhar, A. G., Duflo, E., \& Jackson, M. O. (2013). The diffusion of microfinance. Science, 341(6144), 1236498.

Bargain, O., \& Aminjonov, U. (2020). Trust and compliance to public health policies in times of COVID-19. Journal of Public Economics, 192, 104316.

Barkoczi, D. \& Galesic, M. (2016). Social learning strategies modify the effect of network structure on group performance. Nature Communications, 7(13109).

Barkoczi, P., Analytis, P., \& Wu, C. (2016) Collective search on rugged landscapes: a cross-environmental analysis. Proceedings of the Annual Meeting of the Cognitive Science Society.

Barron, A. T., Huang, J., Spang, R. L., \& DeDeo, S. (2018). Individuals, institutions, and innovation in the debates of the French Revolution. Proceedings of the National Academy of Sciences, 115(18), 4607-4612.

BBC News (2022). Covid map: Coronavirus cases, deaths, vaccinations by country (June 1, 2022). https://www.bbc.com/news/world-51235105

Becker, J., Brackbill, D., \& Centola, D. (2017). Network dynamics of social influence in the wisdom of crowds. Proceedings of the National Academy of Sciences, 114, E5070-E5076.

Benkler, Y., Shaw, A., \& Hill, B.M. (2015). Peer production: A modality of collective intelligence. In T.W. Malone \& M.S. Bernstein (Eds.), Handbook of collective intelligence. MIT Press.

Berdahl, A., Torney, C. J., Ioannou, C. C., Faria, J. J., \& Couzin, I. D. (2013). Emergent sensing of complex environments by mobile animal groups. Science, 339(6119), 574-576.

Berdahl, A.M., Kao, A.B., Flack, A., Westley, P.A., Codling, E.A., Couzin, I.D., Dell, A.I., Biro, D. (2018) Collective animal navigation and migratory culture: from theoretical models to empirical evidence. Philosphical Transactions of Royal Society B, 373(1746):20170009 
Bettencourt, L. M., Cintrón-Arias, A., Kaiser, D. I., \& Castillo-Chávez, C. (2006). The power of a good idea: Quantitative modeling of the spread of ideas from epidemiological models. Physica A: Statistical Mechanics and its Applications, 364, 513-536.

Biele, G., Rieskamp, J., \& Gonzalez, R. (2009). Computational models for the combination of advice and individual learning. Cognitive Science, 33(2), 206-242.

Bikhchandani, S., Hirshleifer, D., \& Welch, I. (1992). A theory of fads, fashion, custom, and cultural change as informational cascades. Journal of Political Economy, 100(5), 992-1026.

Billinger, S., Stieglitz, N., \& Schumacher, T. R. (2014). Search on rugged landscapes: An experimental study. Organization Science, 25(1), 93-108.

Binz, M., Gershman, S. J., Schulz, E., \& Endres, D. (2022). Heuristics from bounded meta-learned inference. Psychological Review.

Biro, D., Sasaki, T., Portugal, S.J. (2016). Bringing a time-depth perspective to collective animal behaviour. Trends in Ecology \& Evolution, 31(7):550-562.

Bonaccio, S., \& Dalal, R. S. (2006). Advice taking and decision-making: An integrative literature review, and implications for the organizational sciences. Organizational Behaviour and Human Decision Processes, 101(2), 127-151.

Bonanno, G. A., \& Jost, J. T. (2006). Conservative shift among high-exposure survivors of the September 11th terrorist attacks. Basic and Applied Social Psychology, 28(4), 311-323.

Boring, E. G. (1923). Intelligence as the tests test it. New Republic, 35(6), 35-37.

Bothos, E., Apostolou, D., \& Mentzas, G. (2012). Collective intelligence with web-based information aggregation markets: The role of market facilitation in idea management. Expert Systems with Applications, 39(1), 1333-1345.

Bowles, S. (2009). Did warfare among ancestral hunter-gatherers affect the evolution of human social behaviours?. Science, 324(5932), 1293-1298.

Bowles, S., \& Gintis, H. (2013). A cooperative species: Human reciprocity and its evolution. Princeton University Press.

Boyd, R., \& Lorberbaum, J. P. (1987). No pure strategy is evolutionarily stable in the repeated prisoner's dilemma game. Nature, 327(6117), 58-59.

Boyd, R., \& Richerson, P. J. (1985). Culture and the evolutionary process. Chicago: University of Chicago Press.

Brown, J. R., \& Enos, R. D. (2021). The measurement of partisan sorting for 180 million voters. Nature Human Behaviour, 1-11.

Brush, E. R., Krakauer, D. C., \& Flack, J. C. (2018). Conflicts of interest improve collective computation of adaptive social structures. Science Advances, 4(1), e1603311.

Budescu, D. V., \& Chen, E. (2015). Identifying expertise to extract the wisdom of crowds. Management Science, 61(2), 267-280.

Caklovic, L., \& Kurdija, A. S. (2017). A universal voting system based on the Potential Method. European Journal of Operational Research, 259(2), 677-688.

Cantor, M., Chimento, M., Smeele, S. Q., He, P., Papageorgiou, D., Aplin, L. M., \& Farine, D. R. (2021). Social network architecture and the tempo of cumulative cultural evolution. Proceedings of the Royal Society B, 288(1946), 20203107.

Cantwell, G. T., Kirkley, A., \& Newman, M. E. J. (2021). The friendship paradox in real and model networks. Journal of Complex Networks, 9(2), cnab011.

Carbone, G., \& Giannoccaro, I. (2015). Model of human collective decision-making in complex environments. The European Physical Journal B, 88(12), 339.

Castellano, C., Fortunato, S., \& Loreto, V. (2009). Statistical physics of social dynamics. Reviews of Modern Physics, $81(2), 591$.

Cavalli-Sforza, L. L., \& Feldman, M. W. (1981). Cultural transmission and evolution: A quantitative approach (No. 16). Princeton University Press.

Centola, D. (2018). How behaviour spreads: The science of complex contagions (Vol. 3). Princeton, NJ: Princeton University Press.

Centola, D. M. (2013). Homophily, networks, and critical mass: Solving the start-up problem in large group collective action. Rationality and Society, 25(1), 3-40. 
Centola, D., \& Macy, M. (2007). Complex contagions and the weakness of long ties. American Journal of Sociology, $113(3), 702-734$.

Christakis, N. A., \& Fowler, J. H. (2010). Social network sensors for early detection of contagious outbreaks. PloS one, 5(9), e12948.

Christakis, N.A. \& Fowler, J. H. (2009). Connected: The Amazing Power of Social Networks and How They Shape Our Lives. HarperPress.

Cialdini, R. B., \& Goldstein, N. J. (2004). Social influence: Compliance and conformity. Annual Review of Psychology, 55, 591-621.

Cialdini, R. B., \& Trost, M. R. (1998). Social influence: Social norms, conformity and compliance. In D.T. Gilbert, S.T. Fiske, \& G.T. Lindzey (Eds.), Handbook of Social Psychology ${ }^{(4}$ th ed., Vol.2, pp. 151-192). Boston: McGrawHill.

Condorcet, M. (1785). Essay on the application of analysis to the probability of majority decisions. Paris, France: Imprimerie Royale.

Conradt, L., \& List, C. (2009). Group decisions in humans and animals: a survey. Philosophical transactions of The Royal Society B: biological sciences, 364(1518), 719-742.

Conradt, L., \& Roper, T. J. (2010). Deciding group movements: where and when to go. Behavioural Processes, 84(3), 675-677.

Cooney, D. B., Morris, D. H., Levin, S. A., Rubenstein, D. I., \& Romanczuk, P. (2022). Social dilemmas of sociality due to beneficial and costly contagion. arXiv preprint arXiv:2202.09905.

Cosmides, L., \& Tooby, J. (1992). Cognitive adaptations for social exchange. The adapted mind: Evolutionary psychology and the generation of culture, 163, 163-228.

Couzin, I. D., \& Krause, J. (2003). Self-organization and collective behaviour in vertebrates. Advances in the Study of Behaviour, 32(1), 10-1016.

Dalege, J., Borsboom, D., van Harreveld, F., \& van der Maas, H. L. (2018). The attitudinal entropy (AE) framework as a general theory of individual attitudes. Psychological Inquiry, 29(4), 175-193.

Dalege, J., Borsboom, D., Van Harreveld, F., Van den Berg, H., Conner, M., \& Van der Maas, H. L. (2016). Toward a formalized account of attitudes: The Causal Attitude Network (CAN) model. Psychological Review, 123(1), 2.

Daley, D. J., \& Kendall, D. G. (1964). Epidemics and rumours. Nature, 204(4963), 1118-1118.

Dalkey, N. C. (1969). The Delphi method: An experimental study of group opinion. Rand Corporation, Santa Monica.

Daniels, B. C., Flack, J. C., \& Krakauer, D. C. (2017). Dual coding theory explains biphasic collective computation in neural decision-making. Frontiers in Neuroscience, 11, 313.

Danileiko, I. \& Lee, M.D. (2017). A model-based approach to the wisdom of the crowd in category learning. Cognitive Science, 42, 861-883.

Davis-Stober, C. P., Budescu, D. V., Dana, J., \& Broomell, S. B. (2014). When is a crowd wise?. Decision, 1(2), 79.

Dawtry, R. J., Sutton, R. M., \& Sibley, C. G. (2015). Why wealthier people think people are wealthier, and why it matters: From social sampling to attitudes to redistribution. Psychological Science, 26, 1389-1400.

De Vincenzo, I., Giannoccaro, I., Carbone, G., \& Grigolini, P. (2017). Criticality triggers the emergence of collective intelligence in groups. Physical Review E, 96(2), 022309.

Deffner, D., \& McElreath, R. (2022). When does selection favor learning from the old? Social Learning in agestructured populations. PloS one, 17(4), e0267204.

Deffner, D., Kandler, A., \& Fogarty, L. (2021). Effective population size for culturally evolving traits. bioRxiv. Available at https://www.biorxiv.org/content/10.1101/2021.09.09.459561v1.full.pdf.

DeGroot, M. H. (1974). Reaching a consensus. Journal of the American Statistical Association, 69(345), 118-121.

Denrell, J. (2005). Should we be impressed with high performance?. Journal of Management Inquiry, 14(3), 292298.

Denrell, J. (2005). Why most people disapprove of me: experience sampling in impression formation. Psychological Review, 112(4), 951.

Derex, M., \& Boyd, R. (2016). Partial connectivity increases cultural accumulation within groups. Proceedings of the National Academy of Sciences, 113(11), 2982-2987.

Derex, M., \& Mesoudi, A. (2020). Cumulative cultural evolution within evolving population structures. Trends in Cognitive Sciences, 24(8), 654-667. 
Devine, D. J., Clayton, L. D., Dunford, B. B., Seying, R., \& Pryce, J. (2001). Jury decision making: 45 years of empirical research on deliberating groups. Psychology, public policy, and law, 7(3), 622.

Di Stefano, A., Scatà, M., La Corte, A., Liò, P., Catania, E., Guardo, E., \& Pagano, S. (2015). Quantifying the role of homophily in human cooperation using multiplex evolutionary game theory. PloS One, 10(10), e0140646.

Douglas, K. M., Uscinski, J. E., Sutton, R. M., Cichocka, A., Nefes, T., Ang, C. S., et al. (2019). Understanding conspiracy theories. Political Psychology, 40, 3-55.

Dubey, A., \& Pentland, A. (2020). Private and byzantine-proof cooperative decision-making. AAMAS 2020, Auckland, New Zealand (pp. 357-365).

Easley, D., \& Kleinberg, J. (2010). Networks, crowds, and markets (Vol. 8). Cambridge: Cambridge university press.

Efferson, C., Lalive, R., Richerson, P. J., McElreath, R., \& Lubell, M. (2008). Conformists and mavericks: the empirics of frequency-dependent cultural transmission. Evolution and Human Behavior, 29(1), 56-64.

Epstein, J. M. (2014). Agent_Zero: Toward neurocognitive foundations for generative social science. Princeton University Press.

Fairbrother, M., Sevä, I. J., \& Kulin, J. (2019). Political trust and the relationship between climate change beliefs and support for fossil fuel taxes: Evidence from a survey of 23 European countries. Global Environmental Change, 59, 102003.

Fang, C., Lee, J., \& Schilling, M. A. (2010). Balancing exploration and exploitation through structural design: The isolation of subgroups and organizational learning. Organization Science, 21(3), 625-642.

Feld, S. L. (1991). Why your friends have more friends than you do. American Journal of Sociology, 96(6), 14641477.

Festinger, L. (1954). A theory of social comparisons processes. Human Relations, 7, 117-140.

Fisher, R.J. (2011). Intergroup conflict. In M. Deutsch, P.T. Coleman, \& E.C. Marcus, E. C. (Eds.). The handbook of conflict resolution: Theory and practice (pp. 176-196). John Wiley \& Sons.

Forrester, J. W. 1968. Principles of Systems. Cambridge MA: Productivity Press.

Fragata, I., Blanckaert, A., Louro, M. A. D., Liberles, D. A., \& Bank, C. (2019). Evolution in the light of fitness landscape theory. Trends in ecology \& evolution, 34(1), 69-82.

Friedkin, N. E., Proskurnikov, A. V., Tempo, R., \& Parsegov, S. E. (2016). Network science on belief system dynamics under logic constraints. Science, 354(6310), 321-326.

Friedman, D. (1998). On economic applications of evolutionary game theory. Journal of Evolutionary Economics, 8(1), 15-43.

Galesic, M., Barkoczi, D., \& Katsikopoulos, K. (2018). Smaller crowds outperform larger crowds and individuals in realistic task conditions. Decision, 5, 1-15.

Galesic, M., Olsson, H., Dalege, J., van der Does, T., \& Stein, D. L. (2021). Integrating social and cognitive aspects of belief dynamics: Towards a unifying framework. Journal of Royal Society Interface.

Galton, F. (1907). Vox populi. Nature, 75(7), 450-451.

Gavrilets, S. (2004) Fitness Landscapes and the Origin of Spe-cies, Princeton University Press

Giannoccaro, I., Galesic, M., Massari, G. F., Barkoczi, D., \& Carbone, G. (2020). Search behaviour of individuals working in teams: A behavioural study on complex landscapes. Journal of Business Research, 118, 507516.

Giannoccaro, I., Massari, G. F., \& Carbone, G. (2018). Team resilience in complex and turbulent environments: The effect of size and density of social interactions. Complexity, 2018.

Gigerenzer, G. (1991). From tools to theories: A heuristic of discovery in cognitive psychology. Psychological Review, 98(2), 254.

Gigerenzer, G. E., Hertwig, R. E., \& Pachur, T. E. (2011). Heuristics: The foundations of adaptive behaviour. Oxford University Press.

Gigerenzer, G., \& Hug, K. (1992). Domain-specific reasoning: Social contracts, cheating, and perspective change. Cognition, 43(2), 127-171.

Gleeson, J. P. (2013). Binary-state dynamics on complex networks: Pair approximation and beyond, Physical Review $X, 3,021004$.

Goldenberg, A., Garcia, D., Halperin, E., \& Gross, J. J. (2020). Collective emotions. Current Directions in Psychological Science, 29(2), 154-160.

Goldstone, R.L. \& Theiner, G. (2017). The multiple, interacting levels of cognitive systems (MILCS) perspective on group cognition. Philosophical Psychology, 30(3). 338-372. 
Goldstone, R.L., Wisdom, T.N., Roberts, M.E., \& Frey, S. (2013). Learning along with others. Psychology of Learning and Motivation, 58. 1-45.

Golub, B., \& Jackson, M. O. (2012). How homophily affects the speed of learning and best-response dynamics. The Quarterly Journal of Economics, 127(3), 1287-1338.

Gonzalez, C., \& Martin, J. M. (2011). Scaling up instance-based learning theory to account for social interactions. Negotiation and Conflict Management Research, 4(2), 110-128.

Gonzalez, C., Ben-Asher, N., Martin, J. \& Dutt, V. (2015). A Cognitive Model of Dynamic Cooperation with Varied Interdependency Information. Cognitive Science, 39, 457-495.

Granovskiy, B., Gold, J. M., Sumpter, D. J., \& Goldstone, R. L. (2015). Integration of social information by human groups. Topics in Cognitive Science, $7(3)$, 469-493.

Grice, H. P. (1975). Logic and conversation. In Speech Acts (pp. 41-58). Brill.

Griffiths, T. L., Callaway, F., Chang, M. B., Grant, E., Krueger, P. M., \& Lieder, F. (2019). Doing more with less: metareasoning and meta-learning in humans and machines. Current Opinion in Behavioral Sciences, 29, 24-30.

Grofman, B., Feld, S. L., \& Owen, G. (1984). Group size and the performance of a composite group majority: Statistical truths and empirical results. Organizational Behavior and Human Performance, 33, 350 -359.

Grofman, B., Owen, G., \& Feld, S. L. (1983). Thirteen theorems in search of the truth. Theory and Decision, 15, 261278.

Gross, J., \& De Dreu, C. K. (2019). The rise and fall of cooperation through reputation and group polarization. Nature Communications, 10(1), 1-10.

Gross, T., \& Blasius, B. (2008). Adaptive coevolutionary networks: a review. Journal of the Royal Society Interface, 5(20), 259-271.

Guilbeault, D., Becker, J., \& Centola, D. (2018). Complex contagions: A decade in review. Complex Spreading Phenomena in Social Systems, 3-25.

Gupta, P., \& Woolley, A. W. (2021, September). Articulating the role of artificial intelligence in collective intelligence: A transactive systems framework. In Proceedings of the Human Factors and Ergonomics Society Annual Meeting (Vol. 65, No. 1, pp. 670-674). Sage CA: Los Angeles, CA: SAGE Publications.

Hahn, U., Hansen, J. U., \& Olsson, E. J. (2020). Truth tracking performance of social networks: How connectivity and clustering can make groups less competent. Synthese, 197, 1511-1541.

Hahn, U., von Sydow, M., \& Merdes, C. (2019). How communication can make voters choose less well. Topics in Cognitive Science, 11(1), 194-206.

Hammond, R. A., \& Ornstein, J. T. (2014). A model of social influence on body mass index. Annals of the New York Academy of Sciences, 1331(1), 34-42.

Hastie, R., \& Kameda, T. (2005). The robust beauty of majority rules in group decisions. Psychological Review, 112(2), 494.

Hastie, R., Penrod, S. D., \& Pennington, N. (2013). Inside the jury. Harvard University Press.

Haven, E. \& Khrennikov, A. (2013). Quantum social science. Cambridge University Press.

Heckathorn, D. D. (1996). The dynamics and dilemmas of collective action. American Sociological Review, $250-277$.

Hein, A. M., Rosenthal, S. B., Hagstrom, Berdahl, A., Torney, C.J., \& Couzin, I. D. (2015). The evolution of distributed sensing and collective computation in animal populations. Elife, 4, e10955.

Heinberg, J. G. (1932). Theories of majority rule. American Political Science Review, 26(3), 452-469.

Hellmann, T., \& Staudigl, M. (2014). Evolution of social networks. European Journal of Operational Research, 234(3), 583-596.

Henderson, W. D. (1985). Cohesion, the human element in combat. National Defense University Press.

Henrich, J. (2004). Demography and cultural evolution: how adaptive cultural processes can produce maladaptive losses - the Tasmanian case. American Antiquity, 69(2), 197-214.

Henrich, J., \& Gil-White, F. J. (2001). The evolution of prestige: Freely conferred deference as a mechanism for enhancing the benefits of cultural transmission. Evolution and Human Behaviour, 22(3), 165-196.

Henrich, J., \& McElreath, R. (2003). The evolution of cultural evolution. Evolutionary Anthropology Issues News and Reviews, 12(3), 123-135.

Henrich, J., Boyd, R., Bowles, S., Camerer, C., Fehr, E., Gintis, H., \& McElreath, R. (2001). In search of homo economicus: behavioral experiments in 15 small-scale societies. American Economic Review, 91(2), 73-78. 
Henrich, J., Chudek, M., \& Boyd, R. (2015). The Big Man Mechanism: how prestige fosters cooperation and creates prosocial leaders. Philosophical Transactions of the Royal Society B: Biological Sciences, 370(1683), 20150013.

Hernantes, J., Rich, E., Laugé, A., Labaka, L., \& Sarriegi, J. M. (2013). Learning before the storm: Modeling multiple stakeholder activities in support of crisis management, a practical case. Technological Forecasting and Social Change, 80(9), 1742-1755.

Hertwig, R., \& Hoffrage, U. (Eds.). (2013). Simple heuristics in a social world. Oxford University Press.

Heyes, C. (2016). Who knows? Metacognitive social learning strategies. Trends in Cognitive Sciences, 20(3), 204213.

Heyes, C. (2018). Cognitive gadgets: The cultural evolution of thinking. Harvard University Press.

Hills, T. T., Todd, P. M., Lazer, D., Redish, A. D., Couzin, I. D., \& Cognitive Search Research Group. (2015). Exploration versus exploitation in space, mind, and society. Trends in cognitive sciences, 19(1), 46-54.

Hinsz, V.B., Tindale, R.S., \& Vollrath, D.A. (1997). The Emerging Conceptualization of Groups as Information Processors. Psychological Bulletin, 121(1). 43-64.

Holland, J. H. (1992). Complex adaptive systems. Daedalus, 121(1), 17-30.

Holling, C. S. (1973). Resilience and stability of ecological systems. Ann. Rev. Ecol. Syst. 4, 1-23.

Hoppitt, W., \& Laland, K. N. (2013). Social learning: an introduction to mechanisms, methods, and models. Princeton University Press.

Jablonka, E., \& Lamb, M. J. (2008). Soft inheritance: challenging the modern synthesis. Genetics and Molecular Biology, 31, 389-395.

Jackson, M. O. (2010). Social and economic networks. Princeton University Press.

Janis, I. L. (1972). Victims of groupthink. Boston: Houghton Mifflin

Jayles, B., Escobedo, R., Cezera, S., Blanchet, A., Kameda, T., Sire, C., \& Theraulaz, G. (2020). The impact of incorrect social information on collective wisdom in human groups. Journal of the Royal Society Interface, 17(170), 20200496.

Jetten, J. and Hornsey, M. J. (2014). Deviance and dissent in groups. Annual Review of Psychology, 65:461-468.

Kallens, P. A. C., Dale, R., \& Smaldino, P. E. (2018). Cultural evolution of categorization. Cognitive Systems Research, 52, 765-774.

Kandler, A., \& Laland, K. N. (2009). An investigation of the relationship between innovation and cultural diversity. Theoretical population biology, 76(1), 59-67.

Kandler, A., \& Powell, A. (2018). Generative inference for cultural evolution. Philosophical Transactions of the Royal Society B: Biological Sciences, 373(1743), 20170056.

Kao, A. B., \& Couzin, I. D. (2019). Modular structure within groups causes information loss but can improve decision accuracy. Philosophical Transactions of the Royal Society B, 374(1774), 20180378.

Kao, A.B., \& Couzin, I.D. (2014) Decision accuracy in complex environments is often maximized by small group sizes. Proceedings of Royal Society B, 281(1784):20133305.

Kaplan, J. (2008) The end of the adaptive landscape metaphor? Biology \& Philosophy. 23, 625-638

Kendal, R. L., Boogert, N. J., Rendell, L., Laland, K. N., Webster, M., \& Jones, P. L. (2018). Social learning strategies: Bridge-building between fields. Trends in Cognitive Sciences, 22(7), 651-665.

Kennedy, W. G. (2012). Modelling human behaviour in agent-based models. In Agent-based models of geographical systems (pp. 167-179). Springer, Dordrecht.

Kerr, N. L., \& Tindale, R. S. (2004). Group performance and decision making. Annu. Rev. Psychol., 55, 623-655.

King, A. \& Cowlishaw, G. (2007). When to use social information: the advantage of large group size in individual decision making. Biology Letters 3(2), 137-139.

Kirke, C. (2010). Military cohesion, culture and social psychology. Defence \& Security Analysis, 26(2), 43-159.

Kline, M.A. (2015). How to learn about teaching: An evolutionary framework for the study of teaching behaviour in humans and other animals. Behavioural and Brain Sciences, 38, 1-71.

Konstantinidis, E., Harman, J. L., \& Gonzalez, C. (2020). Memory patterns for choice adaptation in dynamic environments. Available at https://psyarxiv.com/f34qb/.

Kossinets, G., \& Watts, D. J. (2009). Origins of homophily in an evolving social network. American Journal of Sociology, 115(2), 405-450.

Kozlowski, A. C., Taddy, M., \& Evans, J. A. (2019). The Geometry of Culture: Analyzing the Meanings of Class through Word Embeddings. American Sociological Review, 84(5), 905-949. 
Kozyreva, A., Lewandowsky, S., \& Hertwig, R. (2020). Citizens versus the internet: Confronting digital challenges with cognitive tools. Psychological Science in the Public Interest, 21(3), 103-156.

Krafft, P. M., Shmueli, E., Griffiths, T. L., Tenenbaum, J. B. \& Pentland, A. S. (2021). Bayesian collective learning emerges from heuristic social learning. Cognition 212, 104469.

Krapivsky, P. L., \& Redner, S. (2003). Dynamics of majority rule in two-state interacting spin systems. Physical Review Letters, 90, 238701.

Kurvers, R. H., Herzog, S. M., Hertwig, R., Krause, J., Carney, P. A., Bolt, A., ... \& Wolf, M. (2016). Boosting medical diagnostics by pooling independent judgments. Proceedings of the National Academy of Sciences, 113(31), 8777-8782.

Kurvers, R. H., Herzog, S. M., Hertwig, R., Krause, J., Moussaid, M., Argenziano, G., ... \& Wolf, M. (2019). How to detect high-performing individuals and groups: Decision similarity predicts accuracy. Science Advances, 5(11), eaaw9011.

Laland, K. N. (2004). Social learning strategies. Animal Learning \& Behaviour, 32, 4-14.

Laplace, P.S. (1886). Essai Philosophique sur les Probabilites. Introduction to Theorie Analytique des Probabilites, Oeuvres Complotes De Laplace, Paris: Gauthier-Villars.

Lazer, D. M., Pentland, A., Watts, D. J., Aral, S., Athey, S., Contractor, N., ... \& Wagner, C. (2020). Computational social science: Obstacles and opportunities. Science, 369(6507), 1060-1062.

Lazer, D., \& Friedman, A. (2007). The network structure of exploration and exploitation. Administrative Science Quarterly, 52(4), 667-694.

Le Bon, G. (1895). Crowd psychology. Reprinted by G. Anagnostides Publications.

Lee, E., Karimi, F., Wagner, C., Jo, H. H., Strohmaier, M., \& Galesic, M. (2019). Homophily and minority-group size explain perception biases in social networks. Nature Human Behaviour, 3(10), 1078-1087.

Lejarraga, T., Lejarraga, J., \& Gonzalez, C. (2014). Decisions from experience: How groups and individuals adapt to change. Memory \& Cognition, 42 (8), 1384-1397.

Lerman, K., Yan, X., \& Wu, X. Z. (2016). The" majority illusion" in social networks. PloS one, 11(2), e0147617.

Levinthal, D. A. Adaptation on rugged landscapes. Management Science, 43, 934-950.

Lewis, K. \& Herndon, B. (2011). Transactive Memory Systems: Current Issues and Future Research Directions. Organization Science, 22(5). 1254-1265.

List, C., \& Puppe, C. (2009). Judgment aggregation: A survey. In in P. Anand, C. Puppe and P. Pattanaik (eds.), Oxford Handbook of Rational and Social Choice. Oxford University Press.

Loreto, V., Haklay, M., Hotho, A., Servedio, V. D., Stumme, G., Theunis, J., \& Tria, F. (Eds.). (2016). Participatory sensing, opinions and collective awareness. Springer.

Lu, J. G., Jin, P., \& English, A. S. (2021). Collectivism predicts mask use during COVID-19. Proceedings of the National Academy of Sciences, 118(23).

Maani, K. E., and R. Y. Cavana. 2007. Systems Thinking, System Dynamics: Managing Change and Complexity, Second Edition. Auckland: Pearson Education New Zealand.

MacCoun, R.J. \& Hix, W.M. (2010). Unit Cohesion and Military Performance, in Sexual Orientation and U.S. Military Personnel Policy: An Update of RAND's 1993 Study, RAND.

Macy, M. W., \& Willer, R. (2002). From factors to actors: Computational sociology and agent-based modeling. Annual Review of Sociology, 143-166.

Malone, T. W., \& Bernstein, M. S. (Eds.). (2015). Handbook of collective intelligence. MIT Press.

Malone, T. W., Laubacher, R., \& Dellarocas, C. (2009). Harnessing crowds: Mapping the genome of collective intelligence. Available at http://ssrn.com/abstract=1381502.

Mannes, A. E., Soll, J. B., \& Larrick, R. P. (2014). The wisdom of select crowds. Journal of Personality and Social Psychology, 107(2), 276.

Martin, J.M., Gonzalez, C., Juvina, I., \& Lebiere, C., (2014). A Description-Experience Gap in Social Interactions: Information about Interdependence and Its Effects on Cooperation. Journal of Behavioural Decision Making. 27:349-362

Mason, W. A., Conrey, F. R. and Smith, E. R. (2007). Situating Social Influence Processes: Dynamic, Multidirectional Flows of Influence Within Social Networks. Personality and Social Psychology Review, 11(3).

Mason, W. A., Jones, A. and Goldstone, R. L. (2008). Propagation of Innovations in Networked Groups. Journal of Experimental Psychology: General, 137(3). 
Massari, G. F., Giannoccaro, I., \& Carbone, G. (2019). Are distrust relationships beneficial for group performance? The influence of the scope of distrust on the emergence of collective intelligence. International Journal of Production Economics, 208, 343-355.

Mata, R., Schooler, L. J., \& Rieskamp, J. (2007). The aging decision maker: cognitive aging and the adaptive selection of decision strategies. Psychology and aging, 22(4), 796.

McCright, A. M., \& Dunlap, R. E. (2011). The politicization of climate change and polarization in the American public's views of global warming, 2001-2010. The Sociological Quarterly, 52(2), 155-194.

McPherson, M., Smith-Lovin, L., \& Cook, J. M. (2001). Birds of a feather: Homophily in social networks. Annual Review of Sociology, 27(1), 415-444.

Mechkova, V., Lührmann, A., \& Lindberg, S. I. (2017). How much democratic backsliding?. Journal of Democracy, 28(4), 162-169.

Mehlhorn, K., Newell, B. R., Todd, P. M., Lee, M. D., Morgan, K., Blthwaite, V. A., ... \& Gonzalez, C. (2015). Unpacking the exploration-exploitation tradeoff: A synthesis of human and animal literatures. Decision, 2(3), 191.

Mellers, B., Ungar, L., Baron, J., Ramos, J., Gurl, B., Fincher, K., ... \& Murray, T. (2014). Psychological strategies for winning a geopolitical forecasting tournament. Psychological science, 25(5), 1106-1115.

Mesoudi, A. (2016). Cultural evolution: a review of theory, findings and controversies. Evolutionary biology, 43(4), 481-497.

Mesoudi, A., \& Thornton, A. (2018). What is cumulative cultural evolution?. Proceedings of the Royal Society B, 285(1880), 20180712.

Mesoudi, A., Chang, L., Dall, S. R., \& Thornton, A. (2016). The evolution of individual and cultural variation in social learning. Trends in ecology \& evolution, 31(3), 215-225.

Mesoudi, A., Chang, L., Murray, K., \& Lu, H. J. (2015). Higher frequency of social learning in China than in the West shows cultural variation in the dynamics of cultural evolution. Proceedings of the Royal Society B: Biological Sciences, 282(1798), 20142209.

Milgram, Stanley. (1967). The Small World Problem. Psychology Today, 1, 61-67.

Miller, J. H. \& Page, S. E. (2007). Complex adaptive systems: An introduction to computational models of social life. Princeton University Press.

Molleman, L., Tump, A. N., Gradassi, A., Herzog, S., Jayles, B., Kurvers, R. H., \& van den Bos, W. (2020). Strategies for integrating disparate social information. Proceedings of the Royal Society B, 287(1939), 20202413.

Moore, E. F., \& Shannon, C. E. (1956). Reliable circuits using less reliable relays. Journal of the Franklin Institute, 262(3), 191-208.

Moreira, J. A., Pacheco, J. M., \& Santos, F. C. (2013). Evolution of collective action in adaptive social structures. Scientific Reports, 3(1), 1-6.

Moreno, J. L. (1951). Sociometry, experimental method and the science of society. Beacon House.

Morgan, T., Rendell, L., Ehn, M., Hoppitt, W., and Laland, K. (2011). The evolutionary basis of human social learning. Proc. R. Soc. B Biol. Sci. 279, 653-662.

Morone, F. \& Makse, H. A. (2015). Influence maximization in complex networks through optimal percolation. Nature 524, 65-68.

Moussaïd, M., Helbing, D., \& Theraulaz, G. (2011). How simple rules determine pedestrian behaviour and crowd disasters. Proceedings of the National Academy of Sciences, 108(17), 6884-6888.

Mullen, B., \& Copper, C. (1994). The relation between group cohesiveness and performance: An integration. Psychological Bulletin, 115(2), 210-227.

Newman, M. E. (2003). The structure and function of complex networks. SIAM review, 45(2), 167-256.

Newton, J. (2018). Evolutionary game theory: A renaissance. Games, 9(2), 31.

Nitzan S. and J. Paroush (1984), The Significance of Independent Decisions in Uncertain Dichotomous Choice Situations, Theory and Decision, 17, 47-60.

Odling-Smee, F. J., Laland, K. N., \& Feldman, M. W. (2013). Niche construction: the neglected process in evolution (MPB-37). Princeton university press.

Olson, M. E., Arroyo-Santos, A., \& Vergara-Silva, F. (2019). A user's guide to metaphors in ecology and evolution. Trends in ecology \& evolution, 34(7), 605-615. 
Olsson, H. (2021). The strategy aggregation effect in judgment. Manuscript submitted for publication. Available at https://psyarxiv.com/agpk5.

Olsson, H., \& Loveday, J. (2015). A comparison of small crowd selection methods. In D. C. Noelle, R. Dale, A. S. Warlaumont, J. Yoshimi, T. Matlock, C. D. Jennings, \&, P. P. Maglio (Eds.), Proceedings of the ThirtySeventh Annual Conference of the Cognitive Science Society (pp. 1769-1774). Austin, TX: Cognitive Science Society.

Oprea, R. (2020). What makes a rule complex?. American economic review, 110(12), 3913-51.

Ostrom, E. (1990). Governing the commons: The evolution of institutions for collective action. Cambridge University Press.

Ostrom, E. (2010). Beyond markets and states: polycentric governance of complex economic systems. American Economic Review, 100(3), 641-72.

Ostrowski, B., Williams Woolley, A., \& Haan, K. W. (2022). Translating Member Ability Into Group Brainstorming Performance: The Role of Collective Intelligence. Small Group Research, 53(1), 3-40.

Page, S. E. (2008). The Difference: How the Power of Diversity Creates Better Groups, Firms, Schools, and SocietiesNew Edition. Princeton University Press.

Parhami, B. (1994). Voting algorithms. IEEE transactions on reliability, 43(4), 617-629.

Payne, J. W., Bettman, J. R., \& Johnson, E. J. (1988). Adaptive strategy selection in decision making. Journal of Experimental Psychology: Learning, Memory, and Cognition, 14, 534-552.

Penrod, S. \& R. Hastie (1979), Models of Jury Decision Making: A Critical Review, Psychological Bulletin, 86, 462.

Penrose, L. S. (1946). The elementary statistics of majority voting. Journal of the Royal Statistical Society, 109(1), 53-57.

Pentland, A. (2014). Social Physics: How social networks can make us smarter. Penguin.

Pentland, A. (2021, October). Optimized Human-Al Decision Making: A Personal Perspective. In Proceedings of the 2021 International Conference on Multimodal Interaction (pp. 778-780).

Perc, M., Jordan, J. J., Rand, D. G., Wang, Z., Boccaletti, S., \& Szolnoki, A. (2017). Statistical physics of human cooperation. Physics Reports, 687, 1-51.

Pescetelli, N., \& Yeung, N. (2021). The role of decision confidence in advice-taking and trust formation. Journal of Experimental Psychology: General, 150(3), 507.

Pescetelli, N., Rees, G., \& Bahrami, B. (2016). The perceptual and social components of metacognition. Journal of Experimental Psychology: General, 145(8), 949.

Pivato, M. (2017). Epistemic democracy with correlated voters. Journal of Mathematical Economics, 72, 51-69.

Plott, C. R. (1967). A notion of equilibrium and its possibility under majority rule. The American Economic Review, 57(4), 787-806.

Poisson, S. D. (1837). Recherches sur la probabilité des jugements en matière criminelle et en matière civile. Bachelier.

Prentice, D., \& Miller, D. T. (1993). Pluralistic ignorance and alcohol use on campus: Some consequences of misperceiving the social norm. Journal of Personality and Social Psychology, 64, 243-256.

Proskurnikov, A. V., \& Tempo, (2017). A tutorial on modelling and analysis of dynamic social networks. Part I. Annual Reviews in Control, 43, 65-79.

Rand, D. G., Arbesman, S., \& Christakis, N. A. (2011). Dynamic social networks promote cooperation in experiments with humans. Proceedings of the National Academy of Sciences, 108(48), 19193-19198.

Rawlings, B., Flynn, E., \& Kendal, R. (2017). To copy or to innovate? The role of personality and social networks in children's learning strategies. Child Development Perspectives, 11(1), 39-44.

Ready, E., \& Price, M. H. (2021). Human behavioral ecology and niche construction. Evolutionary Anthropology: Issues, News, and Reviews, 30(1), 71-83.

Redner, S. (2019). Reality Inspired Voters Models: A Mini-review, arXiv:1811.11888.

Rendell, L., Boyd, R., Cownden, D., Enquist, M., Eriksl, K., Feldman, M. W., ... \& Laland, K. N. (2010). Why copy others? Insights from the social learning strategies tournament. Science, 328(5975), 208-213.

Richerson, P. J., \& Boyd, R. (2008). Not by genes alone: How culture transformed human evolution. University of Chicago press.

Riedl, C., Kim, Y. J., Gupta, P., Malone, T. W., \& Woolley, A. W. (2021). Quantifying collective intelligence in human groups. Proceedings of the National Academy of Sciences, 118(21), e2005737118. 
Rieskamp, J., \& Hoffrage, U. (2008). Inferences under time pressure: How opportunity costs affect strategy selection. Acta Psychologica, 127(2), 258-276.

Rieskamp, J., \& Otto, P. E. (2006). SSL: a theory of how people learn to select strategies. Journal of Experimental Psychology: General, 135(2), 207.

Rogers, E. M. (1995). Diffusion of innovations. Simon \& Shuster.

Ross, L., Greene, D., \& House, P. (1977). The "false consensus effect": An egocentric bias in social perception and attribution processes. Journal of experimental social psychology, 13(3), 279-301.

Ryan, P. A., Powers, S. T., \& Watson, R. A. (2016). Social niche construction and evolutionary transitions in individuality. Biology \& philosophy, 31(1), 59-79.

Saaty, T. L. (1989). Group decision making and the AHP. In The analytic hierarchy process (pp. 59-67). Springer, Berlin, Heidelberg.

Saja, A. M., Teo, M., Goonetilleke, A., \& Ziyath, A. M. (2021). A critical review of social resilience properties and pathways in disaster management. International Journal of Disaster Risk Science, 12(6), 790-804.

Salganik, M. J. (2019). Bit by bit: Social research in the digital age. Princeton University Press.

Sasaki, T., Biro, D. (2017) Cumulative culture can emerge from collective intelligence in animal groups. Nature Communications, 8:15049.

Savage, L. J. (1972). The foundations of statistics. Courier Corporation.

Schmelz, K. (2021). Enforcement may crowd out voluntary support for COVID-19 policies, especially where trust in government is weak and in a liberal society. Proceedings of the National Academy of Sciences, 118(1), e2016385118.

Schmelz, K., \& Bowles, S. (2021). Overcoming COVID-19 vaccination resistance when alternative policies affect the dynamics of conformism, social norms, and crowding out. Proceedings of the National Academy of Sciences, 118(25).

Shalizi, C. R., \& Thomas, A. C. (2011). Homophily and contagion are generically confounded in observational social network studies. Sociological methods \& research, 40(2), 211-239.

Shi, F., Teplitskiy, M., Duede, E., \& Evans, J. A. (2019). The wisdom of polarized crowds. Nature Human Behaviour, 3(4), 329-336.

Siders, A. R., \& Pierce, A. L. (2021). Deciding how to make climate change adaptation decisions. Current Opinion in Environmental Sustainability, 52, 1-8.

Simon, H. A. (1976). From substantive to procedural rationality. In 25 years of economic theory (pp. 65-86). Springer, Boston, MA.

Simon, H. A. (1978). Rationality as process and as product of thought. The American economic review, 68(2), 1-16.

Simon, Herbert A. (1956). Rational Choice and the Structure of the Environment. Psychological Review. 63 (2): 129138.

Şimşek, Ö., \& Buckmann, M. (2015). Learning from small samples: An analysis of simple decision heuristics. In Advances in Neural Information Processing Systems (NIPS) 28.

Sloman, S. J., Goldstone, R. L., \& Gonzalez, C. (2021). A Social Interpolation Model of Group Problem-Solving. Cognitive Science, 45(12), e13066.

Sloman, S., Goldstone, R. L., \& Gonzalez, C. (2019). Complex exploration dynamics from simple heuristics in a collective learning environment. Proceedings of the Annual Conference of the Cognitive Science Society, pp. 2818-2824.

Smaldino P. E. (2023). Modeling social behavior: Mathematical and agent-based models of social dynamics and cultural evolution. Princeton University Press.

Smaldino P. E., Flamson, T. J., McElreath, R. (2018) The evolution of covert signaling. Scientific Reports 8, 4905.

Smaldino, P. E. (2014). The cultural evolution of emergent group-level traits. Behavioral and Brain Sciences, 37(3), 243.

Smaldino, P. E., \& Epstein, J. M. (2015). Social conformity despite individual preferences for distinctiveness. Royal Society Open Science, 2(3), 140437.

Smaldino, P. E., \& Jones, J. H. (2021). Coupled dynamics of behaviour and disease contagion among antagonistic groups. Evolutionary Human Sciences, 3.

Smith, E. A., Mulder, M. B., \& Hill, K. (2001). Controversies in the evolutionary social sciences: A guide for the perplexed. Trends in Ecology \& Evolution, 16(3), 128-135.

Smith, E. R. \& Zárate, M. A. (1992). Exemplar-based model of social judgment. Psychological Review, 99, 3-21. 
Smolla, M., \& Akçay, E. (2019). Cultural selection shapes network structure. Science Advances, 5(8), eaaw0609.

Solé, R., Moses, M., \& Forrest, S. (2019). Liquid brains, solid brains. Philosophical Transactions B, 374.

Sorkin, R. D., West, R., \& Robinson, D. E. (1998). Group performance depends on the majority rule. Psychological Science, 9, 456-463.

Stasser, G., \& Titus, W. (1985). Pooling of unshared information in group decision making: Biased information sampling during discussion. Journal of personality and social psychology, 48(6), 1467.

Stephens, W., Sieckelinck, S., \& Boutellier, H. (2021). Preventing violent extremism: A review of the literature. Studies in Conflict \& Terrorism, 44(4), 346-361.

Steyvers, M. \& Miller, B. (2015). Cognition and collective intelligence. In T.W. Malone \& M.S. Bernstein (Eds.), Handbook of Collective Intelligence. MIT Press.

Stubbersfield, J. M., Tehrani, J. J., \& Flynn, E. G. (2015). Serial killers, spiders and cybersex: Social and survival information bias in the transmission of urban legends. British Journal of Psychology, 106(2), 288-307.

Surowiecki, J. (2005). The wisdom of crowds. Anchor.

Tajfel, H. (1981). Human groups and social categories: Studies in social psychology. Cup Archive.

Täuscher, K. (2017). Leveraging collective intelligence: How to design and manage crowd-based business models. Business Horizons, 60(2), 237-245.

Tetlock, P. E., \& Gardner, D. (2016). Superforecasting: The art and science of prediction. Random House.

Thomas, W. I. \& Swaine Thomas, D. The child in America: Behaviour problems and programs. (Knopf, 1928).

Torney, C. J., Berdahl, A., \& Couzin, I. D. (2011). Signalling and the evolution of cooperative foraging in dynamic environments. PLoS Computational Biology, 7(9), e1002194.

Tranter, B., \& Booth, K. (2015). Scepticism in a changing climate: A cross-national study. Global Environmental Change, 33, 154-164.

Tump, A. N., Pleskac, T. J., \& Kurvers, R. H. (2020). Wise or mad crowds? The cognitive mechanisms underlying information cascades. Science Advances, 6(29), eabb0266.

Tump, A. N., Wolf, M., Romanczuk, P., \& Kurvers, R. H. (2022). Avoiding costly mistakes in groups: the evolution of error management in collective decision making. PLoS Computational Biology, 18(8), e1010442.

Turner, M. E., \& Horvitz, T. (2001). The dilemma of threat: Group effectiveness and ineffectiveness under adversity. In Turner, M.E. (Ed.), Groups at work: Theory and Research (pp. 445-470). New York: Psychology Press.

Turner, R. H., \& Killian, L. M. (1957). Collective behaviour (Vol. 3). Englewood Cliffs, NJ: Prentice-Hall.

Turoff, M., Hiltz, S. R., Bañuls, V. A., \& Van Den Eede, G. (2013). Multiple perspectives on planning for emergencies: An introduction to the special issue on planning and foresight for emergency preparedness and management.

Vallacher, R. R., Read, S. J., \& Nowak, A. (Eds.). (2017). Computational social psychology. Routledge.

van Benthem, J. (2011). Logical Dynamics of Information and Interaction. Cambridge University Press.

van der Does, T., Stein, D. L., Fedoroff, N. \& Galesic, M. (2021). Moral and social foundations of beliefs about scientific issues: Predicting and understanding belief change. Available at https://doi.org/10.31219/osf.io/zs7dq.

Van Der Maas, H. L., Dolan, C. V., Grasman, R. P., Wicherts, J. M., Huizenga, H. M., \& Raijmakers, M. E. (2006). A dynamical model of general intelligence: The positive manifold of intelligence by mutualism. Psychological Review, 113(4), 842.

Van Swol, L. M., \& Sniezek, J. A. (2005). Factors affecting the acceptance of expert advice. British Journal of Social Psychology, 44(3), 443-461.

Wang, Z., Wang, L., Szolnoki, A., \& Perc, M. (2015). Evolutionary games on multilayer networks: a colloquium. The European Physical Journal B, 88(5), 1-15.

Watts, D. J., \& Dodds, P. S. (2007). Influentials, networks, and public opinion formation. Journal of Consumer Research, 34(4), 441-458.

Watts, D. J., \& Strogatz, S. H. (1998). Collective dynamics of 'small-world' networks. Nature, 393(6684), 440-442.

Whalen, A., Cownden, D., \& Laland, K. (2015). The learning of action sequences through social transmission. Animal Cognition, 18(5), 1093-1103.

Wimsatt, W. C. (1972). Complexity and organization. In PSA: Proceedings of the biennial meeting of the Philosophy of Science Association (Vol. 1972, pp. 67-86). D. Reidel Publishing.

Wisdom, T. N., Song, X., \& Goldstone, R. L. (2013). Social learning strategies in networked groups. Cognitive Science, 37(8), 1383-1425. 
Woolley, A. W., Aggarwal, I., \& Malone, T. W. (2015). Collective intelligence and group performance. Current Directions in Psychological Science, 24(6), 420-424.

Woolley, A. W., Chabris, C. F., Pentland, A., Hashmi, N., \& Malone, T. W. (2010). Evidence for a collective intelligence factor in the performance of human groups. Science, 330(6004), 686-688.

Yamagishi, T., \& Hashimoto, H. (2016). Social niche construction. Current Opinion in Psychology, 8, $119-124$.

Yaniv, I. (2004). Receiving other people's advice: Influence and benefit. Organizational Behaviour And Human Decision Processes, 93(1), 1-13.

Young, H. P. (2009). Innovation diffusion in heterogeneous populations: Contagion, social influence, and social learning. American Economic Review, 99(5), 1899-1924. 